Projectnr.: 805.71.833.01

Prodira

Project leader: J.D. van Klaveren

Report 2004.008

November 2004

\title{
Estimation of the acute dietary exposure to pesticides using the probabilistic approach and the point estimate methodology
}

The generation of work examples using food consumption data from the Netherlands and Sweden

Polly E. Boon, Sanna Lignel1 ${ }^{1)}$, Jacob D. van Klaveren, Evelyn I.M. Tjoe Nij

${ }^{1)}$ The National Food Administration, Sweden

Business Unit: Safety \& Health

Group: Databases, Risk Assessment \& Supply Chain Management

This project was partly funded by the European Commission as part of the "Study on Probabilistic Assessment Consumer Training (B-1 3330/SANCO/2002584)" and partly by the European Crop Protection Association (ECPA).

RIKILT - Institute of Food Safety

Bornsesteeg 45, 6708 PD Wageningen, the Netherlands

P.O. Box 230, 6700 AE Wageningen, the Netherlands

Tel: +310317475422

Fax: +31 0317417717

Internet: www.rikilt.wur.nl 
Copyright 2004, RIKILT - Institute of Food Safety.

The client is allowed to publish this report in an integral way and to give this report for perusal to a third party. Without approval in writing of RIKILT - Institute of Food Safety it is not allowed:

- to publish this report partial;

- to use this report or title of this report for setting up calls, to conduct legal procedures, for advertising or non-adverting and for acquisition in general;

- to use the name of RIKILT - Institute of Food Safety apart from author of this report.

\section{EXTERNAL MAILING LIST:}

National Food Administration, Sweden (Dr. L. Busk, Dr. A. Glyn, Dr. A. Andersson, Dr. S. Lignell, Mr. B-G. Ericsson, Dr. A. Strömberg)

The Food and Consumer Product Safety Authority (VWA), The Hague (Prof.dr.ir. W. de Wit, Dr.ir. H.P.J.M. Noteboom, Drs. B.W. Ooms)

The Food and Consumer Product Safety Authority (VWA), Inspectorate for Health Protection and Veterinary Public Health, The Hague (Drs. H.J. Jeuring)

The Food and Consumer Product Safety Authority (VWA), Inspectorate for Health Protection and Veterinary Public Health, Amsterdam (Dr.ir. H. van der Schee, Drs. R. Hittenhausen-Gelderblom) Ministry of Health, Welfare and Sport, The Hague (Dr.ir. R.J. Dortland, Drs. J.W. Dornseiffen) Ministry of Agriculture, Nature and Food quality, department VVA, The Hague (Dr. R.M.C. Theelen, Drs. N.M.I. Scheidegger)

Ministry of Agriculture, Nature and Food quality, department Agriculture, The Hague (Dr.ir. H. de Heer)

Board for the Authorization of Pesticides (CTB), Wageningen (Dr. J.H. Krook, Dr. L. Messchendorp) The Plant Protection Service, Wageningen (Ir. E. Muller)

The Netherlands Nutrition Centre, The Hague (Ir. L.R. van Nieuwland, Dr.ir. L. Jansen)

European Commission, DG Health and Consumer Protection, Brussels, Belgium (Dr. B. Drukker, Dr. L.M. Plaza)

European Food Safety Authority (EFSA), Scientific Expert Services, Unit Pesticide Risk Assessment (Miss. A. Friel, Mr. L. Mohimont)

Biometris, Wageningen UR, Wageningen (Ir. W.J. de Boer, Dr. H. van der Voet)

Syngenta, Cheshire, UK (Dr. K. Travis)

Bayer Crop Science B.V., Mijdrecht (Dr. C. Groeneveld, Dr. H. Mattaar)

Bayer Crop Science B.V., Monheim, Germany (Dr. O. Klein)

Ministère de l'Economie et des Finances, Laboratoire interégional de la DGCCRF, Massy, France

(Dr. B. Declercq)

Federal Institute for Risk Assessment, Berlin, Germany (Dr. U. Banasiak)

National Institute of Public Health and the Environment, Bilthoven (Dr. B.C. Ossendorp)

Ministère de l'agriculture, de la pêche, de l'alimentation et des affairs rurales, Direction Genérale de l'Alimentation, Paris, France (Mrs. S. Malezieux)

Danish Institute for Food and Veterinary Research, Søborg, Denmark (Dr. A. Petersen, Mrs. K.

Granby, Dr. D. Brocca Nilsson)

Austrian Agency for Health and Food Safety, Vienna, Austria (Mrs. H. Reich) 
Federal Office for Consumer Protection and Food Safety, Division Plant Protection Products, Braunschweig, Germany (Dr. K. Hohgardt)

Department of Agriculture and Food, Pesticide Control Service, Dublin, Ireland (Dr. J. Acton, Mr. D. Murphy)

Departamento de Proteccíon Vegetal, Instituto Nacional de Investigacíon y Technología Agraria y Alimentaria (INIA), Madrid, Spain (Dr. M.L. Fernández-Cruz)

Pesticide Safety Directorate (PSD), Human Health Branch, York, UK (Mr. P. Hamey, Dr. S. Burden) Hellenic Ministry of Agriculture, Department of Pesticides, Athens, Greece (Ms. K. Kokkinaki, Dr. M. Kastanias)

Direcção-Geral de Protecção das culturas (DGPC), Residues Evaluation Team, Oeiros, Portugal (Mrs. T. Mendonça)

Plant Product Inspection Centre, Pesticide Division, Helsinki, Finland (Mrs. T. Makinen)

Ministry of Agriculture and Forestry, Department of Agriculture, Helsinki, Finland (Dr. P.-L. Penttilä) European Food Safety Authority (EFSA), Plant Health, Plant Protection Products and their Residues (PPR), Brussels, Belgium (Dr. M. Dunier-Thomann) Instituto Sperimentale per la Patologia Vegetale, Rome, Italy (Dr. E. Conte) Instituto Superiore di Santità, Lab. Tossicologia Applicata, Rome, Italy (Dr. A. Santilio) National Chemicals Inspectorate (Keml), Pesticide Registration, Solna, Sweden (Mr. B. Isaksson) Service Public Federal Santé Publique, Sécurité de la Chaîne Alimentaire et Environnement, Brussels, Belgium (Mrs. S. Farrah)

Ministero della Salute, Direzione Generale Sanità Pubblica Veterinaria Alimenti e Nutrizione, Rome, Italy (Dr. A. Desideri)

Exponent International Ltd, Harrogate, UK (Mrs. C. Harris) 

SUMMARY

$1 \quad$ INTRODUCTION 5

2 METHODS $\quad 7$

2.1 Food consumption data from the Netherlands $\quad 7$

$\begin{array}{lll}2.2 & \text { Food consumption data from Sweden } & 7\end{array}$

$\begin{array}{lll}2.3 \text { Residue levels } & 7\end{array}$

2.4 Age groups 7

2.5 Point estimate 8

2.6 Probabilistic modelling 8

3 WORK EXAMPLES 9

3.1 Work example 1: Point estimate vs. probabilistic modelling 9

3.2 Work example 2: Concept of 'consumers only' 13

3.3 Work example 3: Effect of processing 15

$\begin{array}{ll}3.4 & \text { Work example 4: Effect of variability } \\ 3.5 & 19\end{array}$

3.5 Work example 5: Meaning of different endpoints 22

3.6 Work examples 6 and 7: Stability of the tail 25

4 CONCLUSIONS

REFERENCES

ANNEX 1 Point estimate approach

ANNEX 2 Variability in residue levels within composite samples

ANNEX 3N Characteristics of the different foods used in the calculations of the acute exposure with the point estimate and the probabilistic approach in the Dutch work examples

ANNEX 3S Characteristics of the different foods and summary statistics of the food consumption levels used in the calculations of the acute exposure with the point estimate and the probabilistic approach in the Swedish work examples

ANNEX 4 Summary statistics of the food consumption levels used in probabilisticmodelling in the Dutch work examples 
RIKILT Rapportnummer 2004.008 


\section{SUMMARY}

This report deals with the generation of work examples using food consumption data from the Netherlands and Sweden to facilitate the understanding of probabilistic modelling of dietary exposure to pesticides by risk managers. Imaginary field trial residue data was made up to be as useful as possible to show the potential of probabilistic modelling. In total seven work examples were generated in which different aspects of acute dietary exposure assessment to pesticides and the use of the probabilistic approach were addressed.

In work example 1 the point estimate approach was compared with the probabilistic approach using the same input data. This work example showed that the point estimate resulted in higher estimations of exposure compared to the probabilistic approach, resulting from the conservative assumptions underlying the point estimate (one high level for both consumption and residue, high default variability factor). It was demonstrated that with the probabilistic approach all consumption levels and field trial residue levels available could be used in one analysis, enabling a better use of the available data. Also all foods contributing to the exposure could be addressed simultaneously in one analysis, as opposed to only one food at a time in the point estimate. In this way a more holistic approach to risk is possible.

Work example 2 addressed the concept of 'consumers only'. The example showed that, when exposure could occur via the consumption of more than one food, this concept could result in risk estimates that are difficult to interpret in probabilistic modelling, because the underlying database contains both consumers and non-consumers of the specific food items. This may hamper a clear risk management decision. It was also shown, when addressing only the consumers, that the exposure was influenced by the percentage of the population that consumes such a product. When that percentage was very low the exposure increased more compared to the situation where the whole population (consumers and non-consumers) was considered (e.g. kiwi fruit) than when the food was consumed by a large majority of the population (e.g. apple in The Netherlands or apple/pear in Sweden).

The effect of processing on the acute exposure assessment was demonstrated in work example 3 , showing clearly that processing influenced the exposure assessment. It was demonstrated that with the probabilistic approach the risk assessor can address different types of food processing simultaneously with each food item being linked to the correct variability factor (e.g. variability applied when addressing apples and pears eaten whole, but not when addressing apples and pears mixed in juices and nectars). This is not possible with the point estimate.

In work example 4 the effect of introducing variability in different ways into the probabilistic exposure assessment was studied. This resulted in different outcomes. The beta assumption on distribution reflects best what happens in real life (residue levels of individual units can be either lower, equal or higher than the corresponding composite sample level) and the maximum residue level to be sampled is bounded at an upper level.

The meaning of different endpoints in the acute exposure distribution created by probabilistic assessment was discussed in work example 5. It was argued that when a certain critical percentile of exposure exceeds the acute reference dose (ARfD) a critical examination of the intakes contributing to 
this, by studying for example the highest ten exposure levels with their corresponding consumption and residue levels, would be very useful, giving the risk manager an insight in the reliability of the upper percentiles. Related to this it was argued that the uncertainty factors used to derive an ARfD should be considered in relation to the occurrence probability of the exposure exceeding the ARfD. When this probability is very low (e.g. lower than $10^{-4}$ or $10^{-5}$ ) one can argue whether such a risk is acceptable or not.

In two work examples we studied the stability of the tail of the distribution. In work example 6 this was done by examining the effect of the number of iterations on the upper percentiles of the exposure distribution. The results showed that the number of iterations should be sufficient for making a confident estimation of a certain percentile. The number of iterations depends on the number of consumption data and residue levels available, and on the percentile of interest. The more data available the more combinations will be possible of food consumption and residue level, resulting in a need for a higher number of iterations. Also more iterations will be necessary to estimate higher percentiles of the exposure distribution ( $\geq$ P99.9) with confidence.

In work example 7 the stability of the tail was examined by studying the effect of the presence in the food consumption database of consumers with an extreme food consumption pattern (e.g. an infant consuming $2 \mathrm{~kg}$ of apples) or the presence of an outlier in the residue level database. It was evident that an outlier (high consumption or residue level) affected the result of an exposure assessment depending on the magnitude of the outlier compared to the other data present in the data set and on the largeness of the data set available. The effect was more evident on the P99.99 and maximum exposure level simulated than on the P99.9. It was argued that when outliers are present in the data, it is always important to visualise them (quality check on the data, for example related to reporting mistakes in the food consumption database), and to discuss the meaning of these outliers on a possible decision about the compound addressed. For example, it can be argued to what extent individuals with extreme dietary habits should be protected or that general advices concerning healthy eating habits should suffice.

This document demonstrates clearly the potential of the probabilistic approach when dealing with acute dietary exposure assessment of pesticide residues compared to the current methodology used. This methodology is also applicable for data from other countries, and, more importantly, others can be trained to perform risk assessments with the same model using their own data. Different aspects of risk assessment were addressed to help risk managers to understand better and to interpret the results of a probabilistic exposure assessment. The results of this document form the basis for the development of draft guidelines on the use of probabilistic exposure assessment in the safety evaluation of pesticides in the EU-market. 


\section{INTRODUCTION}

On 18 December 1998 the Scientific Committee on Plants (SCP) expressed an opinion regarding the inclusion of aldicarb in Annex 1 to Directive 91/414 concerning the placing of plant protection products on the market [1]. The SCP was also asked to reflect on dietary risk assessment regarding acutely toxic compounds and described the current approach (point estimate) and the probabilistic approach in the annex of the opinion.

\section{Point estimates}

At present, the acute dietary exposure to pesticides is calculated using point estimates. In these estimates a single high residue concentration is multiplied with a single high consumption level for each commodity addressed and divided by a single mean consumer body weight value. In this way a single value for the estimation of the dietary exposure is derived. To determine whether the consumer risk is acceptable, the estimated dietary intake is compared to the short-term dietary intake endpoint, the acute reference dose (ARfD). The point estimate approach has proved to be extremely useful since the estimates are simple to make and relatively easy to understand.

However, it has been recognised that residue levels are not single values but may be derived from a distribution of possible levels. This also applies for food consumption levels: consumption values may range from those consumers never eating the food addressed to those that consume large amounts on a daily basis. Consumers also come in a large range of body weights and people can consume more than one food per day containing the same pesticide. In the point estimate you can only address one food at a time.

\section{Probabilistic modelling}

Probabilistic modelling, another method to calculate the acute dietary exposure to pesticides, takes the above-mentioned issues into account. Furthermore the result is a distribution of all possible exposure levels that may occur in a population as opposed to just one single exposure level resulting from the point estimate approach. These dietary intake distributions provide both the likelihood and the magnitude of a certain level of dietary intake. Comparison of the exposure levels with the ARfD will then give information on the acceptability of consumer risk from these residues.

Probabilistic modelling (also commonly referred to as Monte Carlo analysis) is particularly useful in acute dietary intake estimates in that the probability of a consumer eating more than one food each containing high pesticide residues during one meal or one day can be assessed. This contrasts with "point estimates" of acute dietary intake where it is at present only possible to consider one food commodity at a time. The Monte Carlo approach has been validated by comparing the approach with real pesticide residue intake measured by a duplicate diet study [2,3]. From this validation study it was concluded that the Monte Carlo simulations are indeed a scientifically justified improvement of methodology in pesticide exposure assessment.

Until this year a few probabilistic assessments were mentioned in monographs evaluated by ECCO working groups. During a workshop on Acute Dietary Risk Assessment on 22-23 April 2002, the chair of the ECCO working group indicated that ever since the above mentioned opinion of the SCP, probabilistic risk assessment was hampered by a lack of understanding and a lack of guidance. 
Therefore a study was tendered by the European Commission (PACT project) with the following objectives: 1) to organise a training for EU regulators to familiarise them with probabilistic modelling of acute dietary exposure to pesticide residues, 2) the generation of work examples, and 3) the development of draft guidelines on the use of probabilistic exposure assessment. This report deals with the second aim: the generation of work examples.

\section{Work examples}

The aim of these work examples is to facilitate the understanding of the results of probabilistic risk assessment by risk managers. The examples should:

1. enable a clear comparison between results generated by the point estimate methodology and the probabilistic approach using the same data

2. address the meaning of different endpoints in the pesticide exposure distribution created by probabilistic assessment

3. contain a sensitivity analysis of major assumptions and the stability of the details under different conditions

4. address different age groups including young children

5. demonstrate applicability of the MCRA model in datasets from more than one country

Work examples were generated both with consumption data from the Netherlands and Sweden, to facilitate the understanding of probabilistic modelling and to address different points raised above. The work examples were generated by RIKILT - Institute of Food Safety, Wageningen University and Research Centre, the Netherlands and by The National Food Administration, Sweden, in the "Study on Probabilistic Assessment Consumer Training (B-1-3330/SANCO/2002584)”. 


\section{METHODS}

\subsection{Food consumption data from the Netherlands}

Dutch consumption levels of different foods used in the work examples were derived from the Dutch National Food Consumption Survey (DNFCS) of 1997/1998 [4,5]. In this survey 6,250 respondents aged 1-97 years (of which 530 young children, aged 1-6 years) recorded their food intake over two consecutive days. The amount eaten was weighed accurately. The unit of intake for the calculations is $24 \mathrm{~h}$ in order to obtain random daily consumption patterns. In this way 12,500 eating 'moments' were available for the total Dutch population and 1,060 moments for young children. With the use of the conversion model Primary Agricultural Products (CPAP), developed at the RIKILT - Institute of Food Safety, the consumption of food products, as recorded in the DNFCS, was translated to the consumption of raw agricultural commodities [6]. In this way the residue concentrations analysed in raw agricultural commodities (RACs) could be linked directly to consumption.

\subsection{Food consumption data from Sweden}

Swedish food consumption data used were derived from the Swedish food consumption survey "Riksmaten" performed in 1997-98 [7]. This is a dietary survey performed in 1997 and 1998 among 1,211 persons, aged 18-74 years. Participants were asked to record their food consumption during 7 consecutive days, resulting in 8,477 eating 'moments'. Amounts consumed were estimated based on a portion size guide with photographs.

In Sweden no conversion model to translate foods as eaten into RACs is available. Because of this, mixed foods and processed foods including the food item of interest were not included in the analyses. Another problem with the available Swedish consumption data is that it is impossible to separate consumption of certain foods from each other (e.g. apple and pear). Therefore changes were made compared to the foods used in the Dutch work examples. These changes are indicated in the text.

\subsection{Residue levels}

Residue data used in the work examples were made up to be as useful as possible to show the potential of probabilistic modelling. The number and range of levels resemble those to be found in supervised field trials. Any similarity with real substances is entirely based on coincidence. For the levels used see annex $3 \mathrm{~N}$ and $3 \mathrm{~S}$.

\subsection{Age groups}

For the Dutch population the pesticide residue intake was calculated using the point estimate and probabilistic approach for the general population (1-97 years) and for young children (1-6 years). For the Swedish population the calculation of residue intake was restricted to the adult population (18-74 years). 


\subsection{Point estimate}

To generate the work examples the point estimate approach as defined in the FAO Manual on the Submission and Evaluation of Pesticide Residue Data and used by the Joint FAO/WHO Meeting on Pesticide Residues (JMPR; [8]; annex 1) was used. For the calculations we applied the unit weights as defined by the UK and listed on the WHO GEMS/Food website ${ }^{1}$. Default variability factors were applied, as listed on the WHO GEMS/Food website (annex 1). We did not apply a variability factor of 3 for all commodities as proposed by the 2003 JMPR [9]. The large portion sizes and body weights of the appropriate age groups from the Netherlands and Sweden were used respectively.

\subsection{Probabilistic modelling}

For probabilistic modelling we used the Monte Carlo Risk Assessment' programme (MCRA; available for registered users at the RIKILT website; [10]). This is an internet based programme developed at the RIKILT in co-operation with Biometris (Wageningen UR) to assess the acute exposure to pesticide residues through the diet using the probabilistic approach.

The programme operates as follows. First it selects randomly a consumer out of the consumption database. The consumption of every single food (that could contain the pesticide of interest) for this person on one day is multiplied with a randomly selected residue concentration out of the residue database for that particular food. After each food consumed by the selected person is multiplied with a selected residue concentration, the residue intake of this consumer is added and stored in the output programme. By repeating this procedure many times an empirical estimate of the acute pesticide exposure distribution is obtained. All estimates of possible intakes are adjusted for the individual's self-reported body weight.

To estimate the different percentiles of the exposure distribution, the analyses were performed with 100,000 iterations. When addressing one food in the group of consumers only in young Dutch children, the analyses were performed with 10,000 iterations, due to the small number of children $(<$ 150) consuming one food.

Variability was accounted for in the probabilistic approach by assuming that residue levels within a composite sample follow a beta distribution as described in annex 2 , unless stated otherwise.

Tables in this report produced with Dutch consumption data are indicated with an "N". Tables produced with Swedish consumption data are indicated with an "S".

\footnotetext{
${ }^{1}$ www.who.int/foodsafety/chem/en/acute_hazard_db3.pdf (10-02-2003)

2 www.who.int/foodsafety/chem/acute_data/en/
} 


\section{WORK EXAMPLES}

\subsection{Work example 1: Point estimate vs. probabilistic modelling}

In work example 1 the point estimate approach is compared with the probabilistic approach using the same input data to enable a clear comparison between the results.

Using Dutch food consumption data point estimates were calculated for compounds A and B, present on three and four foods respectively, for each food - compound combination separately (see annex $3 \mathrm{~N}$ for relevant parameters used in the calculations, such as large portion size (LP), variability factor, unit weight). No effect of processing on the residue levels was assumed. The same calculations were performed with the probabilistic approach using the same input data as for the point estimate. In the probabilistic calculations only consumption levels of foods that also contributed to the derivation of the LPs were incorporated (e.g. LP of apple only includes apples eaten as such and no apples present in apple pie, apple juice; applies also to the data from Sweden). The residue intake estimated with the

Table 1AN. Comparison of the point estimate and the probabilistic approach for two compounds for the total population (consumers and non-consumers), in $\mu \mathrm{g} \mathrm{kg}^{-1} \cdot \mathrm{d}^{-1}$, using Dutch food consumption data (work example 1).

\begin{tabular}{|c|c|c|c|c|c|}
\hline & \multirow[t]{2}{*}{ point estimate } & \multicolumn{3}{|c|}{ probabilistic approach } & \multirow{2}{*}{$\begin{array}{c}\% \text { consumers } \\
\text { on a particular } \\
\text { day }\end{array}$} \\
\hline & & P99.9 & P99.99 & maximum & \\
\hline \multicolumn{6}{|l|}{$\begin{array}{l}\text { compound A } \\
\quad \text { general population }\end{array}$} \\
\hline apple & 4.5 & 3.8 & 10.6 & 20 & $26(3208)$ \\
\hline kiwi & 3.2 & 1.2 & 4.9 & 11.9 & $3(370)$ \\
\hline orange & 71 & 31 & 77 & 265 & $10(1215)$ \\
\hline all foods together & & 33 & 82 & 221 & \\
\hline \multicolumn{6}{|l|}{ children (1- 6 years) } \\
\hline apple & 16.4 & 9.8 & 18.8 & 26 & $30(323)$ \\
\hline kiwi & 12.5 & 4.2 & 10.0 & 17.8 & $4(45)$ \\
\hline orange & 244 & 62 & 197 & 338 & $5(50)$ \\
\hline all foods together & & 60 & 217 & 350 & \\
\hline \multicolumn{6}{|l|}{ compound B } \\
\hline \multicolumn{6}{|l|}{ general population } \\
\hline carrot & 24 & 12.3 & 33 & 74 & $8(1004)$ \\
\hline cauliflower & 119 & 36 & 93 & 236 & $5(645)$ \\
\hline mandarin & 62 & 36 & 93 & 211 & $11(1419)$ \\
\hline tomato & 46 & 31 & 69 & 171 & 14 (1706) \\
\hline all foods together & & 55 & 130 & 371 & \\
\hline \multicolumn{6}{|l|}{ children (1- 6 years) } \\
\hline carrot & 74 & 30 & 68 & 99 & $8(86)$ \\
\hline cauliflower & 258 & 74 & 174 & 389 & $5(51)$ \\
\hline mandarin & 224 & 100 & 213 & 360 & $12(131)$ \\
\hline tomato & 129 & 50 & 138 & 233 & $8(79)$ \\
\hline all foods together & & 125 & 248 & 424 & \\
\hline
\end{tabular}

\footnotetext{
${ }^{1}$ Number in brackets indicates number of consumption days.
} 
probabilistic approach was also calculated for all foods simultaneously. To compare the point estimate outcome with the probabilistic approach, the $99.9^{\text {th }}$ percentile (P99.9) of the exposure distribution, as used by the US Environmental Protection Agency (EPA; [11]), was applied. For reasons of comparison we also reported the P99.99 of exposure and the maximum exposure level simulated. Annex 4 lists the summary statistics of the consumption levels used in the probabilistic approach for the Dutch situation.

To perform the same calculations using the Swedish food consumption data some changes were made. In the Swedish consumption database no distinction can be made between the consumption of apple and pear. Therefore the sum consumption of these foods was used. Similarly, the consumption of orange cannot be separated from that of small citrus (mandarin, clementine, satsuma) and grapefruit. Therefore, the consumption of the whole group was used. Likewise, consumption of cauliflower cannot be distinguished from that of Brussels sprouts and broccoli. Finally, the consumption of peach and nectarine (sum) was used instead of mandarin since the consumption of this fruit cannot be separated from the consumption of other small citrus fruits, orange and grapefruit. To sum up, the following changes in food consumption data were made compared to the Dutch work example:

apple $\rightarrow$ apple/pear

orange $\quad \rightarrow \quad$ orange/small citrus/grapefruit

cauliflower $\rightarrow \quad$ cauliflower/Brussels sprouts/broccoli

mandarin $\rightarrow$ peach/nectarine

For parameters used in the calculations, see annex 3S.

The results from the calculations are listed in table $1 \mathrm{~A}(\mathrm{~N}$ and $\mathrm{S})$. Table $1 \mathrm{~B}(\mathrm{~N}$ and $\mathrm{S})$ lists the ten highest exposure levels to both compounds with their corresponding consumption and residue levels. Calculations performed using both the Dutch and Swedish food consumption data demonstrated clearly that the point estimate resulted in higher estimates of exposure than the probabilistic approach, at least at the P99.9 level of exposure (table 1AN and 1AS). An explanation for this is that in the point estimate only one high food consumption level (LP) is used as opposed to all possible consumption levels in the probabilistic approach (including zero consumption levels). Apart from one high

Table 1AS. Comparison of the point estimate and the probabilistic approach for compound A and B for the total population (consumers and non-consumers), in $\mu \mathrm{g} \mathrm{kg}^{-1} \cdot \mathrm{d}^{-1}$, using Swedish food consumption data (work example 1).

\begin{tabular}{|c|c|c|c|c|c|}
\hline & \multirow{2}{*}{$\begin{array}{c}\text { point } \\
\text { estimate }\end{array}$} & \multicolumn{3}{|c|}{ probabilistic approach } & \multirow{2}{*}{$\begin{array}{c}\% \text { consumers } \\
\text { on a particular } \\
\text { day }\end{array}$} \\
\hline & & P99.9 & P99.99 & maximum & \\
\hline \multicolumn{6}{|l|}{ compound A } \\
\hline apple/pear & 4.1 & 2.9 & 4.7 & 9.7 & $29(2484)$ \\
\hline kiwi & 2.8 & 1.0 & 2.3 & 4.8 & $3.8(321)$ \\
\hline orange/small citrus/grapefruit & 67 & 42 & 81 & 121 & $22(1866)$ \\
\hline all foods together & - & 48 & 85 & 170 & \\
\hline \multicolumn{6}{|l|}{ compound B } \\
\hline carrot & 16 & 8.0 & 22 & 48 & $16(1379)$ \\
\hline cauliflower/Brussels sprouts/ broccoli & 32 & 8.7 & 22 & 28 & $5.2(438)$ \\
\hline peach/nectarine & 81 & 24 & 63 & 123 & $2.7(235)$ \\
\hline tomato & 43 & 37 & 64 & 104 & $32(2730)$ \\
\hline all foods together & - & 44 & 80 & 126 & \\
\hline
\end{tabular}

\footnotetext{
${ }^{1}$ Number in brackets indicates number of consumption days.
} 
Table 1BN. Sampled field trial residue levels $\left(\mathrm{mg} \mathrm{kg}^{-1}\right)$ and consumption levels $(\mathrm{g})$ belonging to the ten highest exposure levels simulated in the Dutch general population, including consumers and non-consumers (work example 1).

\begin{tabular}{|c|c|c|c|c|c|c|c|c|c|c|}
\hline & \multicolumn{10}{|c|}{ top 10 of highest exposure levels } \\
\hline & 1 & 2 & 3 & 4 & 5 & 6 & 7 & 8 & 9 & 10 \\
\hline \multicolumn{11}{|l|}{ compound A } \\
\hline respondent & A & $\mathrm{B}$ & $\mathrm{C}$ & $\mathrm{D}$ & $\mathrm{E}$ & $\mathrm{F}$ & $\mathrm{G}$ & $\mathrm{H}$ & I & $\mathrm{J}$ \\
\hline body weight (kg) & 23 & 74 & 15 & 65 & 78 & 51 & 14 & 57 & 14 & 19 \\
\hline age (years) & 5 & 23 & 2 & 16 & 64 & 36 & 3 & 24 & 3 & 3 \\
\hline total exposure $\left(\mu \mathrm{g}^{\cdot} \mathrm{kg}^{-1} \cdot \mathrm{d}^{-1}\right)$ & 141 & 111 & 86.4 & 84.9 & 82.7 & 82.2 & 80.8 & 77.1 & 73.3 & 72.8 \\
\hline \multicolumn{11}{|l|}{ consumption $(g)$} \\
\hline apple & - & - & - & - & - & - & - & - & - & - \\
\hline kiwi & - & - & - & 162 & - & - & 60 & 135 & - & 108 \\
\hline orange & 170 & 240 & 190 & 200 & 480 & 120 & 180 & 120 & 171 & 120 \\
\hline \multicolumn{11}{|c|}{ residue level $\left(\mathrm{mg}^{\prime} \mathrm{kg}^{-1}\right)$} \\
\hline apple & - & - & - & - & - & - & - & - & - & - \\
\hline kiwi & - & - & - & 0.46 & - & - & 0.00 & 0.00 & - & 0.05 \\
\hline orange & 19.1 & 34.3 & 6.82 & 27.2 & 13.4 & 35.0 & 6.29 & 36.6 & 6.00 & 11.5 \\
\hline \multicolumn{11}{|l|}{ compound B } \\
\hline respondent & $\mathrm{K}$ & $\mathrm{L}$ & $\mathrm{L}$ & $\mathrm{L}$ & M & M & $\mathrm{N}$ & M & 0 & $\mathrm{P}$ \\
\hline body weight (kg) & 14 & 17 & 17 & 17 & 11 & 11 & 36 & 11 & 11 & 30 \\
\hline age (years) & 2 & 4 & 4 & 4 & 1 & 1 & 11 & 1 & 2 & 12 \\
\hline total exposure $\left(\mu \mathrm{g}^{\cdot} \mathrm{kg}^{-1} \cdot \mathrm{d}^{-1}\right)$ & 303 & 253 & 237 & 201 & 156 & 131 & 129 & 128 & 119 & 117 \\
\hline \multicolumn{11}{|l|}{ consumption $(g)$} \\
\hline carrot & - & - & - & - & - & - & - & - & - & - \\
\hline cauliflower & 226 & - & - & - & 113 & - & 200 & 113 & 98.0 & - \\
\hline mandarin & - & 360 & 360 & 360 & 55.0 & 55.0 & - & 55.0 & - & 110 \\
\hline tomato & - & - & - & - & - & - & - & - & - & - \\
\hline \multicolumn{11}{|l|}{ residue level ( $\left.\mathrm{mg}^{\circ} \mathrm{kg}^{-1}\right)$} \\
\hline carrot & - & - & - & - & - & - & - & - & - & - \\
\hline cauliflower & 18.8 & - & - & - & 13.7 & - & 23.1 & 2.21 & 13.4 & - \\
\hline mandarin & - & 12.0 & 11.2 & 9.47 & 3.02 & 26.2 & - & 21.1 & - & 31.8 \\
\hline tomato & - & - & - & - & - & - & - & - & - & - \\
\hline
\end{tabular}

consumption level, the point estimate also addresses only one high (the highest) residue level and a high default variability factor. Another factor that may explain the higher exposure levels calculated with the point estimate approach is that in the point estimate a mean body weight is used which may not correspond with the person consuming the LP. This will result in the estimation of high exposure levels, because the LP may belong to a consumer with a body weight higher than the mean body weight of the population addressed. In the probabilistic approach every consumption level is matched to its corresponding body weight, as reported by the respondents. The P99.99 exposure level and the maximum exposure level exceeded the point estimate in most of the cases (tables 1AN and 1AS). However, these values can be more sensitive to uncertainties in data collection (sample size, reporting mistakes (e.g. over reporting), analytical uncertainties) making these estimations of exposure less reliable (see $§ 3.6$ for further discussion).

When calculating the exposure to both compounds via the consumption of all foods simultaneously, the P99.9 of exposure was between the lowest and highest exposure level calculated with the point estimate per food (group). If in this particular example the ARfD for compound A had been $65 \mu \mathrm{g}^{\mathrm{kg}}$ ${ }^{1} \cdot \mathrm{d}^{-1}$, compound A would not have been allowed for use on orange in the Netherlands or citrus fruits in Sweden following the point estimate, while according to the probabilistic approach, taking into 
Table 1BS. Sampled field trial residue levels $\left(\mathrm{mgkg}^{-1}\right)$ and consumption levels $(\mathrm{g})$ belonging to the ten highest exposure levels simulated in the Swedish general population, including consumers and non-consumers (work example 1).

\begin{tabular}{|c|c|c|c|c|c|c|c|c|c|c|}
\hline & \multicolumn{10}{|c|}{ top 10 of highest exposure levels } \\
\hline & 1 & 2 & 3 & 4 & 5 & 6 & 7 & 8 & 9 & 10 \\
\hline \multicolumn{11}{|l|}{ compound A } \\
\hline respondent & A & B & $\mathrm{C}$ & $\mathrm{D}$ & $\mathrm{E}$ & $\mathrm{F}$ & $\mathrm{G}$ & $\mathrm{H}$ & I & $\mathbf{J}$ \\
\hline body weight (kg) & 58 & 66 & 68 & 63 & 66 & 78 & 65 & 64 & 58 & 76 \\
\hline age (years) & 75 & 20 & 49 & 49 & 20 & 62 & 39 & 53 & 75 & 67 \\
\hline total exposure $\left(\mu \mathrm{g} \mathrm{kg}^{-1} \cdot \mathrm{d}^{-1}\right)$ & 170 & 145 & 126 & 102 & 97 & 94 & 93 & 92 & 88 & 87 \\
\hline \multicolumn{11}{|l|}{ consumption $(g)$} \\
\hline apple/pear & 210 & - & 210 & 105 & - & - & 105 & - & 315 & 105 \\
\hline kiwi & - & - & - & - & - & - & - & - & 65 & - \\
\hline $\begin{array}{r}\text { orange/small citrus/grapefruit } \\
\text { residue level }\left(\mathrm{mg} \mathrm{kg}^{-1}\right)\end{array}$ & 400 & 400 & 400 & 300 & 300 & 500 & 200 & 200 & 600 & 200 \\
\hline apple/pear & 0.17 & - & 0.04 & 0.11 & - & - & - & - & 0.02 & - \\
\hline kiwi & - & - & - & - & - & - & - & - & - & - \\
\hline orange/small citrus/grapefruit & 24.6 & 23.9 & 21.4 & 21.3 & 21.3 & 14.6 & 30.1 & 29.3 & 8.5 & 32.9 \\
\hline \multicolumn{11}{|l|}{ compound B } \\
\hline respondent & $\mathrm{K}$ & $\mathrm{L}$ & M & $\mathrm{N}$ & $\mathrm{O}$ & $\mathrm{P}$ & Q & $\mathrm{L}$ & $\mathrm{R}$ & $\mathrm{L}$ \\
\hline body weight (kg) & 65 & 50 & 75 & 62 & 50 & 72 & 64 & 50 & 62 & 50 \\
\hline age (years) & 21 & 52 & 23 & 23 & 25 & 73 & 71 & 52 & 26 & 52 \\
\hline total exposure $\left(\mu \mathrm{g} \mathrm{kg}^{-1} \cdot \mathrm{d}^{-1}\right)$ & 126 & 123 & 106 & 91 & 90 & 90 & 83 & 82 & 80 & 80 \\
\hline \multicolumn{11}{|l|}{ consumption $(g)$} \\
\hline carrot & - & - & - & - & 90 & - & - & - & 90 & - \\
\hline $\begin{array}{r}\text { cauliflower/Brussels sprouts/ } \\
\text { broccoli }\end{array}$ & - & - & - & - & - & - & - & - & - & - \\
\hline peach/nectarine & 260 & 520 & 390 & 520 & - & 260 & 130 & 520 & - & 520 \\
\hline $\begin{array}{r}\text { tomato } \\
\text { residue level }\left(\mathrm{mg}^{*} \mathrm{~kg}^{-1}\right)\end{array}$ & 130 & 65 & - & - & 130 & - & 65 & 65 & 584 & 65 \\
\hline carrot & - & - & - & - & 2.74 & - & - & - & 1.11 & - \\
\hline cauliflower/Brussels sprouts/ & & & & & & & & & & \\
\hline broccoli & - & - & - & - & - & - & - & - & - & - \\
\hline peach/nectarine & 27.1 & 11.8 & 20.4 & 10.9 & - & 24.9 & 40.7 & 7.8 & - & 7.67 \\
\hline tomato & 8.72 & - & - & - & 32.9 & - & 0.04 & 0.32 & 8.35 & - \\
\hline
\end{tabular}

account all foods simultaneously or separately, compound A would have been considered safe for use on all three foods (or food groups) when using the P99.9 of exposure as reference point.

The probability at which a point estimate exposure may occur in a population can roughly be calculated, and thus be compared with the results of the probabilistic approach. For example, the occurrence probability of the point estimate for orange in Dutch children equals about $10^{-4}(0.05(\%$ consumers) $\times 0.025$ (P97.5 of consumption for eaters only) $\times 0.027$ (probability of sampling maximum residue level out of 37 levels; annex 3$))$. For apple, the probability is about $10^{-3}(0.3 \times 0.025$ $\times 0.033$, respectively). It is evident from table $1 \mathrm{AN}$ that for both foods the probabilistic approach resulted in an occurrence probability of point estimates that were lower than the ones calculated above. A possible explanation for this is that in the point estimate a mean body weight is used, as discussed earlier.

Exposures calculated with the probabilistic approach per food (group) were either comparable (compound A) or higher (compound B) than the exposure calculated for all foods simultaneously. For 
compound A orange (The Netherlands) or citrus fruits (Sweden) were clearly the risk drivers due to high residue levels (annex 3), while for compound B in both countries two foods (or food groups) were important (cauliflower and mandarin in the Netherlands, and tomato and peach/nectarine in Sweden), resulting in a higher exposure level when considered simultaneously. This observation is confirmed in table 1BN and 1BS, which list the ten highest exposure levels to both compounds with their corresponding consumption and residue levels. It is clear that in the exposure distribution intakes via combinations of foods occur. In this example $20 \%$ of top 10 intakes (consumers at risk) simulated using the Dutch data were due to the consumption of a combination of fruits. In the Swedish work example, the percentage of consumers with high intakes caused by a combination of fruits was twice as high, although this might be partly explained by using food groups instead of single fruit items.

Children have generally higher exposure levels per kg body weight than the general population (table $1 \mathrm{AN}$ ), due to higher consumption levels per kg body weight. This is also evident from table 1BN where children were clearly over represented when examining the ten highest exposure levels simulated in the general population.

\section{Conclusion}

In work example 1 it was clearly demonstrated that the point estimate results in higher estimations of exposure compared to the probabilistic approach. With the probabilistic approach all residue levels and all consumption levels can be addressed in one simulation, as well as all foods of interest as opposed to only one food (group) at a time in the point estimate approach. In this way better use is made of the data available, resulting in a more 'holistic' approach to what happens in real life. It has been demonstrated that the upper part of the exposure distribution (consumers with the highest risk) are partly explained by consumption of more than one food item. Children have higher exposure levels compared to the general population.

\subsection{Work example 2: Concept of 'consumers only'}

The point estimate methodology deals only with consumers of the food of interest. We therefore repeated work example 1, now addressing in the probabilistic approach only the eaters of a food. In the total population approach both consumers and non-consumers were addressed in the exposure assessment (as in work example 1).

It is evident from table $2 \mathrm{~N}$ and $2 \mathrm{~S}$ that addressing only the consumers of a certain food (group) resulted in an increase of the P99.9, which now mostly exceeded the point estimate exposures. The increase in exposure level when addressing only the consumers of a certain food compared to the total population demonstrated clearly that the level of increase depended on the percentage of consumers in a population. For example, in the Netherlands kiwi is consumed only by $3 \%$ of the general population (table 1AN). Addressing only the consumers will therefore increase the exposure considerably compared to addressing both consumers and non-consumers (introduction of many zero consumption levels), here with a factor of 6 . For foods consumed by a larger part of the Dutch population, e.g. apple, the P99.9 of exposure increased far less (factor of 1.8, table 2). The increase in exposure when addressing only the consumers compared to the total population (consumers and non-consumers) will thus be higher when the percentage of consumers decreases.

If the ARfD had been $65 \mu \mathrm{g} \mathrm{kg}^{-1} \cdot \mathrm{d}^{-1}$ for compound A and the P99.9 was used as the critical reference point the conclusion for the general Dutch population and the Swedish population would have been 
Table 2N.Comparison of the point estimate and the probabilistic approach $\left(\mu \mathrm{g} \mathrm{kg}^{-1} \cdot \mathrm{d}^{-1}\right)$, where probabilistic calculations were performed for the total population (consumers and nonconsumers) and for consumers only. Simulations were performed with Dutch food consumption data (work example 2).

\begin{tabular}{|c|c|c|c|c|c|}
\hline & \multirow{3}{*}{ point estimate } & \multicolumn{4}{|c|}{ probabilistic approach } \\
\hline & & \multicolumn{2}{|c|}{ total population } & \multicolumn{2}{|c|}{ consumers only } \\
\hline & & P99.9 & P99.99 & P99.9 & P99.99 \\
\hline \multicolumn{6}{|l|}{ compound A } \\
\hline \multicolumn{6}{|l|}{ general population } \\
\hline apple & 4.5 & 3.8 & 10.6 & 6.9 & 15.2 \\
\hline kiwi & 3.2 & 1.2 & 4.9 & 7.3 & 14.5 \\
\hline orange & 71 & 31 & 77 & 81 & 192 \\
\hline all foods together & & 33 & 82 & 53 & 121 \\
\hline \multicolumn{6}{|l|}{ children ( $1-6$ years) } \\
\hline apple & 16.4 & 9.8 & 18.8 & 14.5 & 21.0 \\
\hline kiwi & 12.5 & 4.2 & 10.0 & 13.5 & 22.5 \\
\hline orange & 244 & 62 & 197 & 255 & 410 \\
\hline all foods together & & 60 & 217 & 111 & 277 \\
\hline \multicolumn{6}{|l|}{ compound B } \\
\hline \multicolumn{6}{|l|}{ general population } \\
\hline carrot & 24 & 12.3 & 33 & 37 & 73 \\
\hline cauliflower & 119 & 36 & 93 & 116 & 223 \\
\hline mandarin & 62 & 36 & 93 & 91 & 196 \\
\hline tomato & 46 & 31 & 69 & 61 & 115 \\
\hline all foods together & & 36 & 63 & 83 & 186 \\
\hline \multicolumn{6}{|l|}{ children (1- 6 years) } \\
\hline carrot & 74 & 30 & 68 & 81 & 130 \\
\hline cauliflower & 258 & 74 & 174 & 250 & 410 \\
\hline mandarin & 224 & 100 & 213 & 199 & 341 \\
\hline tomato & 129 & 50 & 138 & 138 & 329 \\
\hline all foods together & & 125 & 248 & 191 & 333 \\
\hline
\end{tabular}

the same as in work example 1. For children however, the P99.9 of exposure via the consumption of all three foods (or food groups) did now exceed the ARfD (table 2N).

When addressing all foods (or food groups) together for consumers only, the P99.9 of exposure was now lower than the highest exposure level per food (group), and not, as in the case of addressing both consumers and non-consumers, equal or higher (table 2N and 2S). One food (group) can thus give a higher exposure level than all foods (food groups) simultaneously. This result is conceptually not logical. The reason for this is that the underlying food consumption database used when addressing more than one food (group) contains persons who are consumers of a certain food (group) (e.g. apple) but non-consumers of other foods (food groups) containing the residue (e.g. orange). This results in an exposure level that is neither total population based nor consumer based. By including more foods (or food groups) that may contain the residue of interest in the analyses, the percentiles of exposure for all foods (food groups) together will decrease and will eventually reach the same value as the foods (food groups) together estimate in the total population approach. This dilution of exposure when considering only consumers of foods may hamper a clear management decision. Therefore, when assessing P99.9 
Table 2S. Comparison of the point estimate and the probabilistic approach $\left(\mu \mathrm{g} \mathrm{kg}^{-1} \cdot \mathrm{d}^{-1}\right)$, where probabilistic calculations were performed for the total population (consumers and non-consumers) and for consumers only. Simulations were performed with Swedish food consumption data (work example 2).

\begin{tabular}{|c|c|c|c|c|c|}
\hline & \multirow{3}{*}{$\begin{array}{c}\text { point } \\
\text { estimate }\end{array}$} & \multicolumn{4}{|c|}{ probabilistic approach } \\
\hline & & \multicolumn{2}{|c|}{ total population } & \multicolumn{2}{|c|}{ consumers only } \\
\hline & & P99.9 & P99.99 & P99.9 & P99.99 \\
\hline \multicolumn{6}{|l|}{ compound A } \\
\hline apple/pear & 4.1 & 2.9 & 4.7 & 3.9 & 6.2 \\
\hline kiwi & 2.8 & 1.0 & 2.3 & 3.0 & 4.5 \\
\hline orange/small citrus/grapefruit & 67 & 42 & 81 & 67 & 97 \\
\hline all foods together & - & 48 & 85 & 54 & 85 \\
\hline \multicolumn{6}{|l|}{ compound B } \\
\hline carrot & 16 & 8.0 & 22 & 17 & 37 \\
\hline cauliflower/Brussels sprouts/broccoli & 32 & 8.7 & 22 & 18 & 38 \\
\hline peach/nectarine & 97 & 24 & 63 & 85 & 123 \\
\hline tomato & 43 & 37 & 64 & 52 & 73 \\
\hline all foods together & - & 44 & 80 & 54 & 92 \\
\hline
\end{tabular}

exposure levels for a residue via the consumption of more than one food (group), the consumers only approach is not suitable and the total population approach should be used.

\section{Conclusion}

Work example 2 showed that when addressing only the consumers of certain foods (food groups) in the analysis, the increase in exposure compared to the total population (consumers and nonconsumers) was influenced by the percentage of the population consuming the foods (food groups). We demonstrated that using the consumers only concept when addressing more than one food (group) could result in a lower overall exposure level compared to the exposure from each food separately. This fact may hamper a clear risk management decision.

\subsection{Work example 3: Effect of processing}

Processing is an important variable to be considered when assessing the exposure to a toxic compound via the diet. Most pesticide analyses are performed in raw agricultural commodities (RACs), including peel and (other) non-edible parts. These commodities are however rarely eaten as such, but undergo some form of processing before consumption. In work example 3 we demonstrate the effect of processing on the dietary exposure in both the point estimate and the probabilistic approach for apple in two sub-examples. In the first example (work example 3A) apple can be consumed as whole apple, apple juice or together. To estimate the point estimate for apple juice, the LP for this food was calculated for the general Dutch population and young children (annex $3 \mathrm{~N}$, compound C). In the Swedish consumption database, consumption of apple cannot be distinguished from pear consumption. Therefore the sum consumption of apple and pear was used. Similarly, the consumption of apple juice is undistinguishable from the consumption of juice/nectar (juice/nectar was a pre-printed alternative in the menu book used in the food consumption survey). Therefore, the consumption of juice and nectar was used instead of the consumption of apple juice. This results in an overestimation of the consumption of apple juice, since it is likely that apple juice constitutes only a small part of the consumption of juice and nectar. 
Table 3AN. Acute dietary intake $\left(\mu \mathrm{g} \mathrm{kg}^{-1} \cdot \mathrm{d}^{-1}\right)$ to compound $\mathrm{C}$ via the consumption of apple and apple juice using Dutch food consumption data (work example $3 \mathrm{~A}$ ).

\begin{tabular}{rccc}
\hline & point estimate & \multicolumn{2}{c}{ probabilistic approach (P99.9) } \\
\cline { 3 - 4 } & & total population & consumers only \\
\hline general population & & & \\
apple & 15.0 & 11.2 & 18.7 \\
apple juice & 2.5 & 11.5 & 11.4 \\
apple + apple juice & - & & 18.0 \\
children (1- 6 years) & 55 & 28 & 43 \\
apple & 55 & 11.5 & 11.7 \\
apple juice & 8.4 & 28 & 37 \\
\hline
\end{tabular}

For residue levels and other parameters used in work example 3 see annex $3 \mathrm{~N}$ and $3 \mathrm{~S}$, compound $\mathrm{C}$, and for a summary of the consumption levels of apple, apple/pear, apple juice and juice/nectar used in the probabilistic approach, see annex 3S (Swedish data) and 4 (Dutch data). Also here, for a valid comparison between the point estimate and the probabilistic approach, we incorporated in the probabilistic approach only those consumption levels of apple, apple/pear, apple juice and juice/nectar that contributed to the derivation of the LPs. When addressing the exposure to compound $\mathrm{C}$ via the consumption of apple juice we applied in the probabilistic approach only the supervised trials median residue level (STMR) as used in the point estimate approach. In the Swedish calculations all field trial residue levels were linked to consumption of juice/nectar (applies also to work example 4 en 7). In that case also no variability factor (case 3 of the point estimate approach [8]) was applied in both approaches.

Exposure levels calculated with the point estimate for apple and apple/pear were similar or higher than those calculated with the probabilistic approach for all age groups, when addressing the total population (consumers and non-consumers; table 3AN and 3AS). In Dutch children also the P99.9 of exposure for consumers only was lower than the point estimate exposure. However for apple juice and juice/nectar, the point estimate resulted in lower exposure levels compared to the probabilistic approach (table $3 \mathrm{AN}$ and $3 \mathrm{AS}$ ). The exposure to compound $\mathrm{C}$ via the consumption of both apple and apple juice was, for both the Dutch general population and children, lower than the point estimate for apple for the total population. Using Swedish consumption data, however, the P99.9 of exposure for apple/pear and juice/nectar was higher than the point estimate of apple/pear. This was very likely due to use of all field trial residue levels when assessing the intake of compound $\mathrm{C}$ via the consumption of

Table 3AS. Acute dietary exposure $\left(\mu \mathrm{g} \mathrm{kg}^{-1} \cdot \mathrm{d}^{-1}\right)$ to compound $\mathrm{C}$ via the consumption of apple/pear and juice/nectar using Swedish food consumption data (work example $3 \mathrm{~A})$.

\begin{tabular}{rccc}
\hline & point estimate & \multicolumn{2}{c}{ probabilistic approach (P99.9) } \\
\cline { 3 - 4 } & & total population & consumers only \\
\hline apple/pear & 4.9 & 5.0 & 6.1 \\
juice/nectar & 2.0 & 4.6 & 6.3 \\
apple/pear + juice/nectar & - & 6.1 & 6.8 \\
\hline
\end{tabular}


Table 3BN. Sampled consumption levels ( $\mathrm{g}$ ) and field trial residue levels $\left(\mathrm{mg}^{\circ} \mathrm{kg}^{-1}\right)$ belonging to the ten highest exposure levels simulated in the general Dutch population, including consumers and non-consumers (work example 3A).

\begin{tabular}{rcccccccccccc}
\hline & \multicolumn{10}{c}{ top 10 of highest exposure levels } \\
\cline { 2 - 11 }$y$ & 1 & 2 & 3 & 4 & 5 & 6 & 7 & 8 & 9 & 10 \\
\hline $\begin{array}{r}\text { consumption }(\mathrm{g}) \\
\text { apple }\end{array}$ & 108 & 72 & 124 & 120 & 135 & 120 & 122 & 135 & 135 & 120 \\
apple juice & - & 250 & 150 & - & - & - & - & 140 & 342 & 150 \\
residue level $\left(\mathrm{mg}^{-1} \mathrm{~kg}^{-1}\right)$ & & & & & & & & & & \\
apple & 7.73 & 8.95 & 5.92 & 5.42 & 5.18 & 4.65 & 8.01 & 5.66 & 5.66 & 5.90 \\
apple juice & - & 0.18 & 0.18 & - & - & - & - & 0.18 & 0.18 & 0.18 \\
\hline
\end{tabular}

juice/nectar, in stead of using only the STMR value as in the Dutch calculations.

It was clear that the point estimate and P99.9 of exposure (both total population and consumers only) for apple and apple/pear was far lower in the Swedish population than in the general Dutch population. This was very likely due to the absence of children in the Swedish food consumption database.

If the ARfD for compound C had been $12 \mu \mathrm{g} \mathrm{kg}^{-1} \cdot \mathrm{d}^{-1}$, the compound would have been admitted on the market based on the probabilistic approach in both the Netherlands and Sweden. However in the Netherlands the point estimate exposure for apple would have resulted in a negative advice for admittance. Table 3BN and 3BS, presenting the consumption and residue levels sampled belonging to the ten highest exposure levels simulated for the general Dutch population and the Swedish population, show that in the Netherlands apple contributed most to the exposure. This was because of high residue levels sampled due to applying variability and not of high consumption levels for apple compared to apple juice. The conclusion that consumption of whole apple was the main risk driver in the Netherlands was confirmed by the results presented in table 3AN, where the exposure calculated with the probabilistic approach for both foods simultaneously resembled most that of the exposure to only apple. In Sweden both apple/pear and juice/nectar contributed highly to the intake, due to higher levels linked apple/pear consumption because of variability, high consumption levels of juice/nectar and not linking the STMR value $\left(0.18 \mathrm{mg}^{\cdot} \mathrm{kg}^{-1}\right)$ to juice/nectar consumption levels.

In the second sub-example (work example 3B), apple or apple/pear could be consumed either without or with peel. Peeling reduced the residue level by $90 \%$ (processing factor $=0.1$ ). For residue levels and other parameters used see annex $3 \mathrm{~N}$ and $3 \mathrm{~S}$, compound $\mathrm{D}$, and for a summary of the consumption

Table 3BS. Samples consumption levels ( $\mathrm{g}$ ) and field trial residue levels $\left(\mathrm{mg}^{\cdot} \mathrm{kg}^{-1}\right.$ ) belonging to the ten highest exposure levels simulated in the Swedish general population, including consumers and non-consumers (work example 3A).

\begin{tabular}{rccccccccccc}
\hline & \multicolumn{10}{c}{ top 10 of highest exposure levels } \\
\cline { 2 - 10 }$y$ & 1 & 2 & 3 & 4 & 5 & 6 & 7 & 8 & 9 & 10 \\
\hline consumption $(\mathrm{g})$ & & & & & & & & & & \\
apple/pear & 525 & - & 210 & - & 105 & 525 & 315 & 210 & 315 & 210 \\
juice/nectar & - & 2200 & 1600 & 2200 & 1530 & - & 400 & 200 & 200 & - \\
residue level $\left(\mathrm{mg}^{\prime} \mathrm{kg}^{-1}\right)$ & & & & & & & & & & \\
apple/pear & 1.68 & - & 1.93 & - & 0.21 & 1.06 & 1.08 & 2.25 & 1.46 & 2.30 \\
juice/nectar & - & 0.36 & 0.24 & 0.28 & 0.36 & - & 0.24 & 0.32 & 0.30 & - \\
\hline
\end{tabular}


Table 3CN. The influence of processing on the acute dietary exposure $\left(\mu \mathrm{gkg}^{-1} \cdot \mathrm{d}^{-1}\right)$ via apple consumption in the Dutch population (work example 3B).

\begin{tabular}{rccc}
\hline & point estimate & \multicolumn{2}{c}{ probabilistic approach (P99.9) } \\
\cline { 3 - 4 } & & total population & consumers only \\
\hline general population & & & \\
no peeling & 12.0 & 13.7 & 24 \\
all peeling & 1.2 & 1.4 & 2.4 \\
58\% peeling/42\% not & - & 10.0 & 15.7 \\
children (1 - 6 years) & & & 44 \\
no peeling & 44 & 33 & 4.4 \\
all peeling & 4.4 & 3.3 & 33 \\
\hline $58 \%$ peeling/42\% not & - & 21 & \\
\hline
\end{tabular}

levels of apple or apple/pear see annex 3S and 4.

In the point estimate only one processing type at a time can be addressed, resulting often in the choice of the worst-case approach (no effect of processing). For example in the case of apples, people can consume their apples either with or without peel. In the point estimate, the worst-case assumption will be that nobody consumes peeled apples as opposed to the optimistic situation where everybody consumes peeled apples (table $3 \mathrm{CN}$ and $3 \mathrm{CS}$ ). In food consumption surveys, there may be information available on the percentage of people consuming their apple with (in the Dutch survey $42 \%$ ) or without peel (in the Dutch survey 58\%). When no information on processing is available from the food consumption survey, general assumptions on processing habits may be derived from other sources (e.g. literature). In the Swedish example, no information on peeling practices was available, and it was therefore assumed that $50 \%$ of the consumers peeled their apple/pear before consumption. When information on processing practices is incorporated in the analyses using the probabilistic approach, a more realistic estimation of exposure is possible compared to the worst-case assumption that nobody peels their apple or apple/pear or the too optimistic situation that everybody peels their apple or apple/pear (table 3CN and 3CS). For example, in the Dutch general population the exposure decreased with more than $20 \%$ compared to the worst-case assumption.

In figure 1 the contribution (\%) of apple with and without peel to the exposure was plotted in the Dutch general population and in young children. As expected in both groups apple with peel contributed most to the exposure $(\geq 85 \%)$, due to the large effect of peeling on the residue level.

\section{Conclusion}

Work example 3 demonstrated that with the probabilistic approach different types of processing per

Table 3CS.The influence of processing on the acute dietary exposure $\left(\mu \mathrm{g} \mathrm{kg}^{-1} \cdot \mathrm{d}^{-1}\right)$ via apple/pear consumption by the Swedish population (work example 3B).

\begin{tabular}{rccc}
\hline & point estimate & \multicolumn{2}{c}{ probabilistic approach (P99.9) } \\
\cline { 3 - 4 } & & total population & consumers only \\
\hline no peeling & 11 & 9.7 & 12 \\
all peeling & 1.1 & 0.95 & 1.2 \\
$50 \%$ peeling/50\% not & - & 8.0 & 11 \\
\hline
\end{tabular}




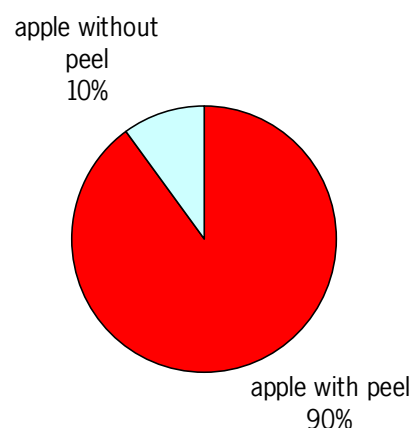

general population

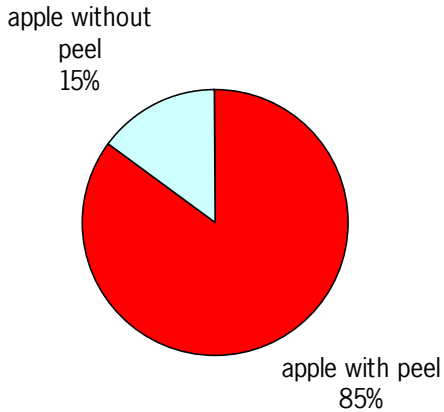

children (1 - 6 years)

Figure 1. Contribution (\%) of apple without and with peel to the total dietary exposure (work example 3, Dutch situation).

food (peeling, not peeling, juicing) can be addressed in one analysis. When doing this each food (group) - processing type combination should be linked to the correct variability factor (e.g. apples eaten whole are subjected to variability, while those mixed in juices are not). In the point estimate approach only one food (group) - processing type combination can be addressed at a time, which can result in worst-case estimations of exposure.

\subsection{Work example 4: Effect of variability}

To account for variability in residue levels between individual units within a composite sample variability factors were introduced in the point estimate approach (annex 1; [12]). In work example 4 we studied the effect of introducing variability factors on the dietary exposure in the probabilistic approach.

We studied the influence of variability on the exposure via the consumption of apple, apple juice and both foods together for the Netherlands and apple/pear, juice/nectar and both food groups together for Sweden. When addressing the exposure via the consumption of apple juice or juice/nectar (case 3 of

Table 4AN. The effect of introducing variability in the probabilistic approach in three different ways $^{1}$ on the acute dietary exposure $\left(\mu \mathrm{g} \mathrm{kg}^{-1} \cdot \mathrm{d}^{-1}\right)$ to compound $\mathrm{C}$ via the consumption of apple and apple juice in the Dutch population. The P99.9 for the total population (consumers and non-consumers) is reported (work example 4).

\begin{tabular}{rrcc}
\hline & \multicolumn{3}{c}{ model variability } \\
\cline { 2 - 4 } apple & 14.0 & 11.2 & 94 \\
apple juice & 6.8 & 6.8 & 6.8 \\
general population & 19.7 & 11.5 & 100 \\
apple + apple juice & & & \\
children (1- 6 years) & 36 & 28 & 246 \\
apple & 11.5 & 11.5 & 11.5 \\
apple juice & 41 & 28 & 256 \\
apple + apple juice & 41 & beta & lognormal \\
\hline
\end{tabular}

${ }^{1}$ For more details see annex 2. 
Table 4AS. The effect of introducing variability in the probabilistic approach in three different ways ${ }^{1}$ on the acute dietary exposure $\left(\mu \mathrm{g} \mathrm{kg}^{-1} \cdot \mathrm{d}^{-1}\right)$ to compound $\mathrm{C}$ via the consumption of apple/pear and juice/nectar juice in the Swedish population. The P99.9 for the total population (consumers and non-consumers) is reported (work example 4).

\begin{tabular}{rccc}
\hline & \multicolumn{3}{c}{ model variability } \\
\cline { 2 - 4 } & Bernoulli & beta & lognormal \\
\hline apple/pear & 8.0 & 4.7 & 64 \\
juice/nectar & 4.8 & 4.8 & 4.8 \\
apple/pear + juice/nectar & 8.2 & 5.9 & 61 \\
\hline
\end{tabular}

${ }^{1}$ For more details see annex 2.

the point estimate approach [8]), no variability factors were applied. Also when including apple and apple juice (Netherlands) or apple/pear and juice/nectar (Sweden) simultaneously in the probabilistic model, variability was only applied to consumption levels of whole apple and apple/pear (see also work example 3). We used in this example the same input data as in work example 3.

Variability was incorporated into the probabilistic model in three ways: 1) using the Bernoulli distribution (comparable with the point estimate), 2) the beta distribution and 3) the lognormal distribution. When assuming a Bernoulli distribution, the number of units within a daily consumption is calculated (based on the unit weight of the food) and for each unit a Bernoulli distribution is used to sample the field trial residue level with probability $(v-1) / v(v=$ variability factor $)$ or a multiple $v$ of it with probability $1 / v$. The Bernoulli distribution is always conservative. The variation in residue levels between units of one composite sample can also be described as following a beta or lognormal distribution. For more details see annex 2. Currently there are no guidelines available on how to incorporate variability into the probabilistic approach.

The Bernoulli assumption on distribution into the analyses resulted in exposure levels that were between those calculated with the beta and lognormal assumptions on distribution (tables 4AN and 4AS). In the 'Bernoulli way' residue levels are selected that are either higher or equal to the original field trial levels, while in the 'beta and lognormal way' also levels below the original field trial levels can be sampled. In reality it is very likely that residue levels within a composite sample are both lower and higher than the value measured. The beta and lognormal assumptions on distribution represent

Table 4BN. Sampled field trial residue levels $\left(\mathrm{mg} \mathrm{kg}^{-1}\right)$ in the general Dutch population belonging to the ten highest exposure levels simulated following three different ways of modelling variability ${ }^{1}$ (work example 4).

\begin{tabular}{|c|c|c|c|c|c|c|c|c|c|c|}
\hline \multirow[b]{2}{*}{ model variability } & \multicolumn{10}{|c|}{ top 10 of highest exposure levels } \\
\hline & 1 & 2 & 3 & 4 & 5 & 6 & 7 & 8 & 9 & 10 \\
\hline \multicolumn{11}{|l|}{ Bernoulli } \\
\hline apple & 6.9 & 5.9 & 3.7 & 6.4 & 3.0 & 5.9 & 3.9 & 6.9 & 5.9 & 6.5 \\
\hline apple juice & - & 0.18 & - & - & - & - & - & 0.18 & - & - \\
\hline \multicolumn{11}{|l|}{ beta } \\
\hline apple & 9.0 & 6.3 & 8.5 & 6.6 & 3.8 & 4.8 & 3.9 & 2.5 & 2.2 & 1.6 \\
\hline apple juice & - & - & - & - & - & - & - & 0.18 & - & - \\
\hline \multicolumn{11}{|l|}{ lognormal } \\
\hline apple & 125 & 176 & 195 & 256 & 143 & 81.1 & 67.9 & 170 & 25.7 & 243 \\
\hline apple juice & 0.18 & - & - & - & - & 0.18 & 0.18 & - & - & - \\
\hline
\end{tabular}

\footnotetext{
${ }^{1}$ For more details see annex 2.
} 
Table 4BS. Sampled field trial residue levels $(\mathrm{mg} / \mathrm{kg})$ in the Swedish population belonging to the ten highest exposure levels simulated following three different ways of modelling variability $^{1}$ (work example 4).

\begin{tabular}{rccccccccccc}
\hline & \multicolumn{10}{c}{ top 10 of highest exposure levels } \\
\cline { 2 - 11 } model variability & 1 & 2 & 3 & 4 & 5 & 6 & 7 & 8 & 9 & 10 \\
\hline Bernoulli & & & & & & & & & & \\
apple/pear & 2.59 & 1.69 & 2.59 & 2.33 & 2.20 & 2.59 & 3.60 & 4.32 & 3.60 & 1.82 \\
juice/nectar & 0.36 & - & 0.10 & 0.24 & - & - & 0.34 & - & - & - \\
beta & & & & & & & & & & \\
$\quad$ apple/pear & - & - & 1.76 & - & - & 2.99 & 1.89 & 0.97 & 0.33 & 3.10 \\
$\quad$ juice/nectar & 0.34 & 0.32 & - & 0.28 & 0.34 & 0.34 & - & 0.34 & 0.36 & 0.28 \\
lognormal & & & & & & & & & & \\
apple/pear & 187.7 & 484.8 & 221.2 & 250.5 & 251.7 & 110.3 & 150.2 & 180.1 & 58.71 & 144.7 \\
juice/nectar & - & - & - & 0.24 & - & 0.18 & 0.20 & 0.20 & - & 0.10 \\
\hline
\end{tabular}

${ }^{1}$ For more details see annex 2.

therefore better what happens in real life. However, modelling the variation in residue levels within one field trial sample with the lognormal assumption resulted in much higher exposure levels compared to both the Bernoulli and beta assumption. With the lognormal approach, no upper limit is defined to the maximum residue level that can be sampled, which resulted in the sampling of very high residue levels compared to the other two approaches, as demonstrated in tables 4BN and 4BS. These levels are unrealistically high when following the original concept of variability as defined during the FAO/WHO Geneva Consultation in 1997 [12].

When, as in work example 3, the ARfD had been $12 \mu \mathrm{g} \mathrm{kg}^{-1} \cdot \mathrm{d}^{-1}$ the compound would have been considered safe for use on the foods addressed in both the Netherlands (based on the general population) and Sweden using the beta assumption for introducing variability in probabilistic calculations of exposure. For children (Netherlands only), the compound would not have been considered safe, independent of the way in which variability was incorporated in the analyses when addressing apple and apple juice simultaneously (table 4AN).

For a better understanding of the effects of variability on the distribution of possible exposures we
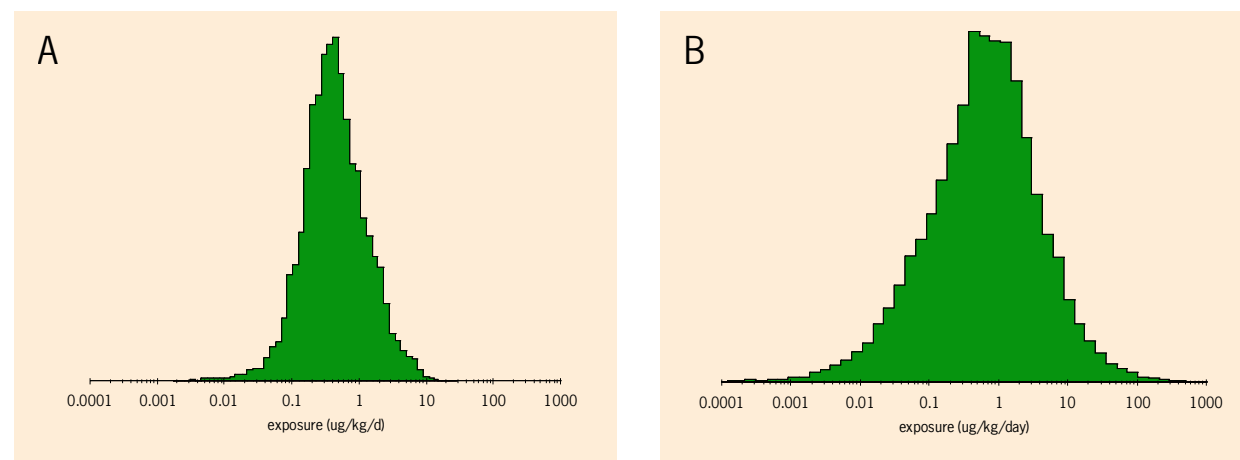

Figure 2. Distribution of the acute dietary exposure $\left(\mu \mathrm{g}^{\cdot} \mathrm{kg}^{-1} \cdot \mathrm{d}^{-1}\right)$ to compound $\mathrm{C}$ in the general population either without (A) or with (B) variability included via the consumption of apple and apple juice. Variability was included following the lognormal distribution (see appendix 3; work example 4). 
plotted a graph of the exposure distribution for the general Dutch population either without (A) and with (B) variability included via the consumption of apple and apple juice (figure 2). Variability was included following the lognormal distribution. It is clear that introducing variability in this way the exposure distribution broadened with both lower exposure levels at the left tail of the distribution as higher exposure levels at the right tail of the distribution.

\section{Conclusion}

In work example 4 we demonstrated that variability can be included in the probabilistic model in different ways, resulting in different outcomes. The way presented here as the beta distribution reflects best what happens in real life (residue levels of individual units can be either lower, equal or higher than the corresponding composite sample level) and the maximum residue level to be sampled is bounded at an upper level.

\subsection{Work example 5: Meaning of different endpoints}

The result of a dietary exposure assessment to pesticides is an exposure distribution. When assessing if the exposure to a compound is of any concern, a percentile of exposure of the distribution is compared with a toxicological reference point. In the case of acutely toxic compounds this reference point is the acute reference dose (ARfD). This ARfD is derived from a no-observed adverse effect level (NOAEL) as generally observed in animal studies after applying a conservative uncertainty factor 100 .

In dietary exposure assessment of pesticides the regulatory threshold risk is at the upper tail of the exposure distribution, e.g. at the P99 or higher. The choice of percentile above which negative health effects may occur, and thus accepting that a certain percentage of the population may be at risk, is a difficult issue. The choice depends among others on the (un)certainties related to the data used in probabilistic modelling. For example how representative is the food consumption survey at your disposal (are all socio-economic classes and age groups relevant present?), and is the food consumption survey sufficiently large to permit characterisation of the overall exposure of the population of interest? It is therefore advisable to always include, when for example the P99.9 exceeds the ARfD, a quality check of the high-end exposures to evaluate the impact of high-end consumption levels (and residue levels) on these exposure levels. It may be advisable to do this, even if the critical percentile does not exceed the ARfD. Such a study may give insight into the sources (food consumption and / or residue level) that contribute to the high-end exposures, facilitating the evaluation of whether these exposures are realistic or not. For example, high consumption levels due to over reporting of food consumption may be a problem when addressing foods with a healthy image such as fruits and vegetables. Another important factor determining the choice of the percentile to be compared with the ARfD, is the question of what percentage of the population to be at risk is considered to be acceptable.

To determine the minimum data requirements for a sensible calculation of upper-tail percentiles in the exposure distribution, the following rule of thumb can be used: the chosen percentile should be contained directly in the data. For example, at least 20 exposure levels are needed to estimate the P95 of exposure and at least 100 to estimate the P99 of exposure. How this 'rule of thumb' will affect minimum data requirements regarding field trial residue data or food consumption data is a complicated issue. This will depend, for example, on the sample size (residue/consumption data), variability within the two databases, and risk drivers in the upper tail of the exposure distribution. 
Table 5AN. Different percentiles of exposure for the general Dutch population and children (16 years), including consumers and non-consumers $\left(\mu \mathrm{g} \mathrm{kg}^{-1} \cdot \mathrm{d}^{-1}\right.$; work example 5).

\begin{tabular}{rcc}
\hline percentiles & general population & children $(1-6$ years $)$ \\
\hline P95 & 0.9 & 1.4 \\
P97.5 & 2.9 & 3.1 \\
P99 & 7.9 & 9.9 \\
P99.9 & 28.6 & 60.5 \\
P99.99 & 64.7 & 146.6 \\
\hline
\end{tabular}

In work example 5 we demonstrate how the choice of percentile to be compared with the ARfD may affect the result of the simulation. For this we studied the exposure via the consumption of three vegetables (beetroot, cucumber and head lettuce) and two fruits (grapefruit and pear) for the Dutch situation. For residue levels used see annex $3 \mathrm{~N}$, compound E, and for a summary of the consumption levels of the foods see annex 4. Because of difficulties of extracting data from the Swedish consumption database on consumption of beetroot, grapefruit and pear, the following changes in foods were made compared to the Dutch analyses:

$\begin{array}{lll}\text { beetroot } & \rightarrow & \text { (sweet) pepper } \\ \text { grapefruit } & \rightarrow & \text { banana } \\ \text { pear } & \rightarrow & \text { peach/nectarine }\end{array}$

A group was created for head lettuce, including three foods: head lettuce, iceberg lettuce and mixed green salad. For mixed green salad a crop conversion factor of 0.19 was introduced, meaning that mixed green salad contains $19 \%$ head lettuce. For parameters used in the Swedish calculations, see annex 3S, compound $\mathrm{E}$

It appears that when selecting the P99.9 (or a lower percentile) as critical percentile, as used by the US EPA [11], we could conclude here that, when the ARfD had been $62 \mu \mathrm{g} \mathrm{kg} \mathrm{bw}^{-1} \mathrm{~d}^{-1}$, there was a reasonable certainty that no harm would occur to the populations addressed (table 5AN and 5AS). The P99.99 exceeded the ARfD of $62 \mu \mathrm{gkg} \mathrm{bw}^{-1} \cdot \mathrm{d}^{-1}$, concluding that both in the Dutch and Swedish population the risk of exceeding the ARfD would be higher than $0.01 \%$. If, however, the ARfD had been $150 \mu \mathrm{gkg} \mathrm{bw}^{-1} \mathrm{~d}^{-1}$, both the P99.9 and P99.99 would not have exceeded the ARfD (table 5AN and 5AS). An evaluation of the highest intake levels for the total population in tables 5BN and 5BS shows that the intake levels above an ARfD of $62 \mu \mathrm{g} \mathrm{kg} \mathrm{bw}^{-1} \cdot \mathrm{d}^{-1}$ were not due to unrealistic high levels of consumption. Residue levels sampled were all below the upper limit of a field trial residue level multiplied with the number of units in a composite sample, showing that the probability of linking an extreme residue level to an extreme consumption level was negligible.

Table 5AS. Different percentiles of exposure for the Swedish population, including consumers and non-consumers $\left(\mu \mathrm{gkg}^{-1} \cdot \mathrm{d}^{-1}\right.$; work example 5).

\begin{tabular}{rc}
\hline percentiles & total population \\
\hline P95 & 5.4 \\
P97.5 & 10 \\
P99 & 19 \\
P99.9 & 47 \\
P99.99 & 89 \\
\hline
\end{tabular}


Table 5BN. Sampled field trial residue levels $\left(\mathrm{mg}^{\cdot} \mathrm{kg}^{-1}\right)$ and consumption levels $(\mathrm{g})$ belonging to the ten highest exposure levels simulated for the Dutch population, including consumers and nonconsumers (work example 5).

\begin{tabular}{|c|c|c|c|c|c|c|c|c|c|c|}
\hline & \multicolumn{10}{|c|}{ top 10 of highest exposure levels } \\
\hline & 1 & 2 & 3 & 4 & 5 & 6 & 7 & 8 & 9 & 10 \\
\hline \multicolumn{11}{|l|}{ general population } \\
\hline respondent & A & $\mathrm{B}$ & B & $\mathrm{C}$ & $\mathrm{D}$ & $\mathrm{E}$ & $\mathrm{F}$ & $\mathrm{G}$ & $\mathrm{H}$ & $\mathrm{C}$ \\
\hline body weight (kg) & 15 & 13 & 13 & 18 & 25 & 16 & 15 & 15 & 13 & 18 \\
\hline age (years) & 4 & 4 & 4 & 3 & 7 & 3 & 2 & 2 & 2 & 3 \\
\hline total exp.1 $\left(\mu \mathrm{g}^{\cdot} \mathrm{kg}^{-1} \cdot \mathrm{d}^{-1}\right)$ & 220 & 139 & 109 & 105 & 97.9 & 91.6 & 83.0 & 70.7 & 68.3 & 67.6 \\
\hline \multicolumn{11}{|l|}{ consumption $(g)$} \\
\hline cucumber & - & - & - & - & - & 5.0 & - & - & - & - \\
\hline grapefruit & & 0.5 & 0.5 & - & - & - & - & - & - & - \\
\hline pear & 154 & 131 & 131 & 300 & 129 & 130 & 90 & 161 & 130 & 300 \\
\hline \multicolumn{11}{|l|}{ residue level (mg kg-1) } \\
\hline cucumber & - & - & - & - & - & 0.1 & - & - & - & - \\
\hline grapefruit & - & 0.5 & 1.3 & - & - & - & - & - & - & - \\
\hline pear & 21.5 & 13.8 & 10.8 & 6.3 & 19.0 & 11.3 & 13.8 & 6.6 & 6.8 & 4.1 \\
\hline \multicolumn{11}{|l|}{ children (1 - 6 years) } \\
\hline respondent & $\mathrm{I}$ & B & $\mathrm{J}$ & K & G & $\mathrm{L}$ & M & $\mathrm{H}$ & $\mathrm{N}$ & B \\
\hline body weight (kg) & 12 & 13 & 17 & 14 & 15 & 10 & 18 & 13 & 16 & 13 \\
\hline age (years) & 1 & 4 & 4 & 2 & 2 & 1 & 3 & 2 & 3 & 4 \\
\hline total exp. $\left(\mu \mathrm{g}^{\cdot} \mathrm{kg}^{-1} \cdot \mathrm{d}^{-1}\right)$ & 282 & 208 & 186 & 175 & 162 & 152 & 147 & 146 & 145 & 144 \\
\hline \multicolumn{11}{|l|}{ consumption $(g)$} \\
\hline beetroot & - & - & - & - & - & - & - & - & 2.1 & - \\
\hline cucumber & - & - & - & - & - & - & - & - & 2.0 & - \\
\hline grapefruit & 0.7 & 0.5 & - & - & - & 0.5 & - & - & 0.3 & 0.5 \\
\hline pear & 129 & 131 & 132 & 128 & 161 & 88.5 & 152 & 130 & 130 & 131 \\
\hline \multicolumn{11}{|l|}{ resdiue level ( $\left.\mathrm{mg}^{\circ} \mathrm{kg}^{-1}\right)$} \\
\hline beetroot & - & - & - & - & - & - & - & - & 0.0 & - \\
\hline cucumber & - & - & - & - & - & - & - & - & 0.5 & - \\
\hline grapefruit & 0.4 & 5.0 & - & - & - & 0.4 & - & - & 0.4 & 1.0 \\
\hline pear & 26.3 & 20.7 & 24.0 & 19.2 & 15.1 & 17.1 & 17.5 & 14.6 & 17.8 & 14.4 \\
\hline
\end{tabular}

${ }^{1}$ exp. $=$ exposure

When establishing acceptable exposure levels also the ARfD's used may be considered. Some ARfD's are very conservative due to lack of sufficient data. Also the uncertainty factor (e.g. 100) used to derive the ARfD may be contemplated. For example, when a P99.99 exceeds the ARfD, there is still a safety margin of 100 compared to the NOAEL as found in an animal study. In the described example using Dutch data, the highest P99.99 was $146.6 \mu \mathrm{g}^{\circ} \mathrm{k} \mathrm{bw}^{-1} \cdot \mathrm{d}^{-1}$ (table 5AN), which was 2.4 times higher than the lowest ARfD considered $\left(62 \mu \mathrm{g} \cdot \mathrm{kg} \mathrm{bw}^{-1} \cdot \mathrm{d}^{-1}\right)$. One can argue, taking into account the probability of such an exposure, whether such a risk is acceptable or not. This issue was addressed in the $35^{\text {th }}$ meeting of the Codex Committee on Pesticide Residues in 2003 [13].

\section{Conclusion}

In work example 5 we showed that the percentile chosen to be compared with a certain ARfD influences conclusions drawn. A critical examination of the exposures contributing to an exceedance of the ARfD, by studying e.g. the highest ten exposure levels with their corresponding consumption and residue levels, provides insight in the reliability of the upper percentiles. Also the uncertainty 
Table 5BS. Sampled field trial residue levels $(\mathrm{mg} / \mathrm{kg})$ and consumption levels $(\mathrm{g})$ belonging to the ten highest exposure levels simulated for the Swedish population, including consumers and non-consumer s(work example 5).

\begin{tabular}{|c|c|c|c|c|c|c|c|c|c|c|}
\hline & \multicolumn{10}{|c|}{ top 10 of highest exposure levels } \\
\hline & 1 & 2 & 3 & 4 & 5 & 6 & 7 & 8 & 9 & 10 \\
\hline respondent & A & B & $\mathrm{C}$ & $\mathrm{C}$ & $\mathrm{D}$ & $\mathrm{E}$ & $\mathrm{F}$ & G & $\mathrm{H}$ & I \\
\hline body weight (kg) & 80 & 94 & 55 & 55 & 55 & 78 & 79 & 80 & 80 & 70 \\
\hline age (years) & 41 & 30 & 73 & 73 & 63 & 29 & 51 & 41 & 53 & 33 \\
\hline $\begin{array}{r}\text { total } \exp ^{1} \cdot\left(\mu \mathrm{gkg} \mathrm{bw}^{-1} \cdot \mathrm{d}^{-1}\right) \\
\text { consumption }(g)\end{array}$ & 202 & 156 & 131 & 128 & 116 & 99.1 & 97.2 & 96.5 & 95.2 & 89.6 \\
\hline pepper & - & - & - & - & 16 & - & - & - & - & 30 \\
\hline cucumber & - & - & - & - & - & - & - & - & - & - \\
\hline banana & 420 & 420 & 210 & 210 & 210 & 315 & 315 & 630 & 315 & 210 \\
\hline head lettuce & 28.5 & - & 35.7 & - & 11.40 & 5.7 & 5.7 & 17.1 & - & - \\
\hline $\begin{array}{l}\text { peach and nectarine } \\
\text { residue level }\left(\mathrm{mg} \mathrm{kg}^{-1}\right)\end{array}$ & 130 & - & - & - & - & - & - & - & - & - \\
\hline pepper & - & - & - & - & 0.33 & - & - & - & - & 0.00 \\
\hline cucumber & - & - & - & - & - & - & - & - & - & - \\
\hline banana & 38.4 & 34.9 & 34.1 & 33.5 & 30.4 & 24.6 & 24.4 & 12.3 & 24.2 & 30.0 \\
\hline head lettuce & 0.04 & - & 0.37 & - & 0.37 & 0.02 & 0.02 & 0.06 & - & - \\
\hline peach and nectarine & 0.23 & - & - & - & - & - & - & - & - & - \\
\hline
\end{tabular}

factors used to derive an ARfD should be considered in relation to the occurrence probability of the exposures exceeding the ARfD.

\subsection{Work examples 6 and 7: Stability of the tail}

To examine the stability of the tail we first studied how the number of iterations influenced the estimation of the upper percentiles ( $\geq$ P95; work example 6). For this we increased the number of iterations in the following way: 50, 500, 5,000, 50,000, 100,000, 250,000, and 500,000. The percentiles reported are P95, P97.5, P99, and P99.9. We also plotted the different exposure distributions per number of iterations. Secondly, the stability of the tail was examined by introducing a high consumption level (due to reporting errors or real) and/or residue level (due to e.g. analytical uncertainties in methods used or real) into the exposure analyses (work example 7). We will also address bootstrap sampling briefly as a way to examine the reliability of the percentiles of exposure.

Work example 6: Number of iterations

In this example we used the residue levels for apple (with / without peel) for compound $\mathrm{C}$ for the Dutch situation and residue levels and consumption levels for apple/pear for the Swedish situation (annex $3 \mathrm{~N}$ and 3S). For a summary of the consumption levels of apple for the Dutch situation see annex 4.

The number of iterations clearly influenced the outcome of the percentiles (tables $6 \mathrm{~N}$ and $6 \mathrm{~S}$ ). With very few iterations (50) the percentiles of exposure $\geq$ P99 and the maximum level simulated were identical and lower than those resulting from more iterations. This is because with 50 intake levels not all possible combinations of consumption and residue level were sampled, making the estimation of any percentile unsure. The P95, P97.5 and P99 reached a stable level from 5,000 iterations onwards for the Dutch data and from 500 iterations for the Swedish data, while the P99.9 and P99.99 became 
Table 6N. Percentiles of exposure and maximum level simulated $\left(\mu \mathrm{gkg}^{-1} \cdot \mathrm{d}^{-1}\right)$ applying a different number of iterations for the general Dutch population, including both consumers and non-consumers (work example 6).

\begin{tabular}{rcccccc}
\hline & \multicolumn{6}{c}{ percentiles and maximum level of exposure } \\
\cline { 2 - 6 } number of iterations & P95 & P97.5 & P99 & P99.9 & P99.99 & max $^{1}$ \\
\hline 50 & 1.2 & 2.1 & 2.7 & 2.7 & 2.7 & 2.7 \\
500 & 0.5 & 1.0 & 2.2 & 6.3 & 6.3 & 6.3 \\
5,000 & 0.6 & 1.3 & 2.9 & 8.5 & 14.4 & 14.4 \\
50,000 & 0.7 & 1.5 & 3.0 & 11.9 & 33.5 & 65.7 \\
100,000 & 0.7 & 1.5 & 3.1 & 11.5 & 25.5 & 40.5 \\
250,000 & 0.7 & 1.5 & 3.0 & 11.4 & 28.3 & 112 \\
500,000 & 0.7 & 1.5 & 3.0 & 10.9 & 26.3 & 89.8 \\
$1,000,000$ & 0.7 & 1.5 & 3.1 & 11.2 & 27.8 & 87.2 \\
\hline
\end{tabular}

\footnotetext{
${ }^{1}$ max $=$ maximum exposure level sampled
}

stable from about 50,000 iterations onwards. This indicates that in this particular example 50,000 iterations would have been sufficient to confidently address the P99 and P99.9.

In figure 3 we plotted the different exposure distributions for the different number of iterations applied for the general Dutch population, including both consumers and non-consumers. The distribution became smoother when the number of iterations increased. In this example the exposure distribution reached its ultimate shape at about 50,000 iterations. The Swedish results were similar.

The number of iterations sufficient to make a confident estimation of a certain percentile is of course dependent on the number of residue data and consumption levels available, and the percentile of interest. The more data there are the more combinations will be possible of food consumption and residue level, resulting in a need for a higher number of iterations. Also more iterations will be necessary for the estimation of higher percentiles of the exposure distribution ( $\geq$ P99.9) with confidence.

Work example 7: Introduction of high consumption/residue level (outliers)

Outliers can be real high levels of food consumption and/or residue concentrations, or mistakes in the

Table 6S. Percentiles of exposure and maximum level simulated $\left(\mu \mathrm{g} \mathrm{kg}^{-1} \cdot \mathrm{d}^{-1}\right)$ applying a different number of iterations for the Swedish population, including consumers and non-consumers (work example 6).

\begin{tabular}{rcccccc}
\hline & \multicolumn{6}{c}{ percentiles and maximum level of exposure } \\
\cline { 2 - 7 } number of iterations & P95 & P97.5 & P99 & P99.9 & P99.99 & max $^{1}$ \\
\hline 50 & 2.6 & 3.7 & 3.7 & 3.7 & 3.7 & 3.7 \\
500 & 1.6 & 2.4 & 3.4 & 5.6 & 5.6 & 5.6 \\
5,000 & 1.7 & 2.3 & 3.2 & 5.8 & 9.5 & 9.5 \\
50,000 & 1.5 & 2.0 & 2.8 & 5.0 & 7.9 & 10.8 \\
100,000 & 1.7 & 2.4 & 3.3 & 6.0 & 9.3 & 11.5 \\
250,000 & 1.7 & 2.4 & 3.4 & 6.0 & 8.5 & 12.2 \\
500,000 & 1.7 & 2.4 & 3.3 & 5.9 & 8.8 & 12.7 \\
\hline
\end{tabular}

\footnotetext{
${ }^{1} \max =$ maximum exposure level sampled
} 

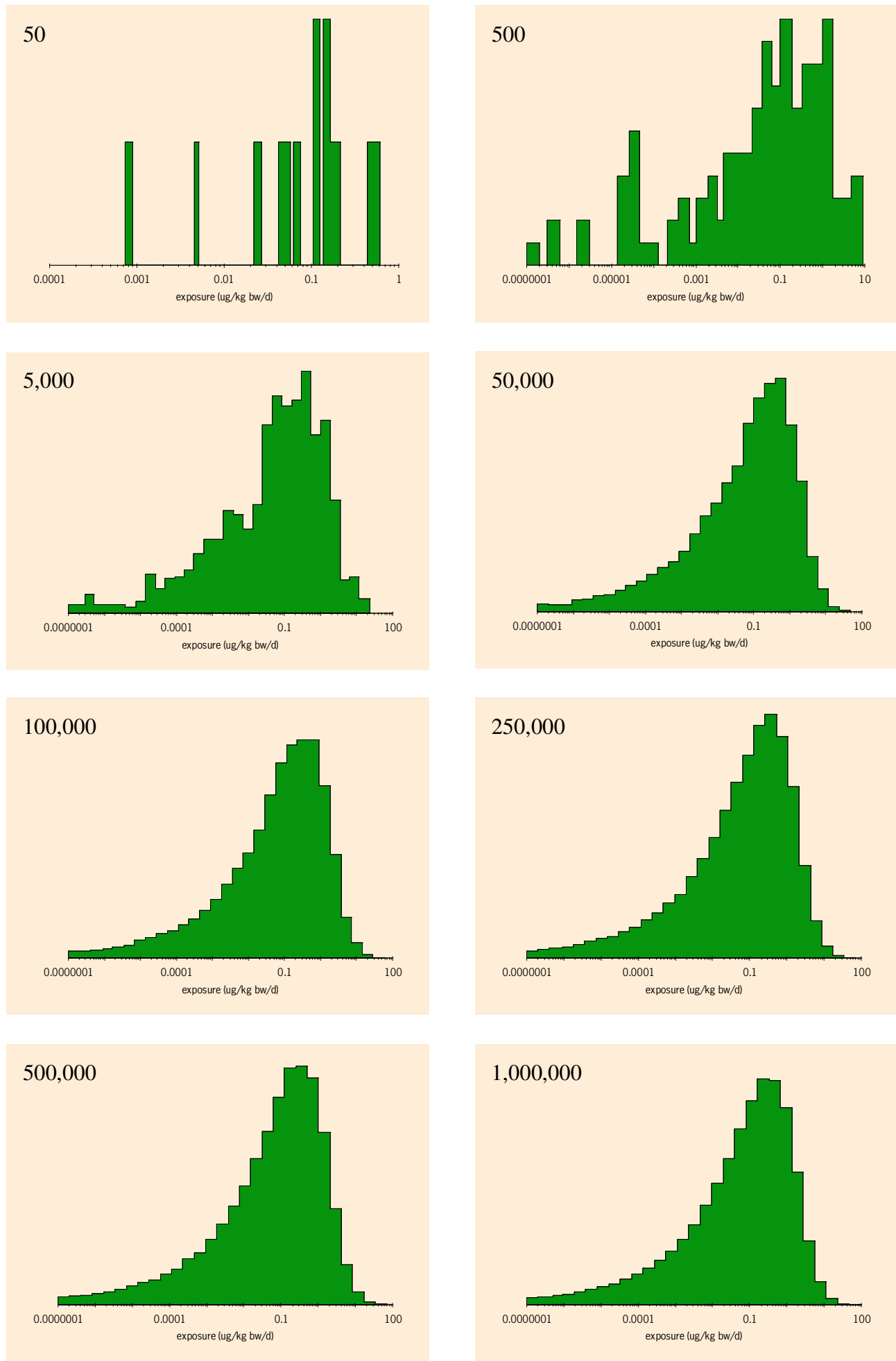

Figure 3. Distributions of exposure $\left(\mu \mathrm{gkg}^{-1} \cdot \mathrm{d}^{-1}\right)$ depending on number of iterations for the general Dutch population, including consumers and non-consumers (work example 6).

database (e.g. an infant consuming $2 \mathrm{~kg}$ of potato). When real extreme values occur in the databases it 
is a complicated risk management discussion on how to deal with these extreme values. For example, within the UK the Food Standard Agency reported a daily swordfish consumption of $100 \mathrm{~g}$ each day. The question was raised how to protect such an extreme consumer against an elevated heavy metal exposure. Regarding this point it can be argued to what extent individuals with extreme dietary habits should be protected or that general advices concerning healthy eating habits (e.g. eat varied, do not consume fatty fish more than twice a week) should suffice. In these situations it is always important to judge extreme values and to make them visible in tables.

To examine the influence of an outlier on the exposure assessment, extreme consumption or residue levels were introduced in the Dutch and Swedish data. For the Dutch example the exposure to compound $\mathrm{C}$ via the consumption of apple was used (annex 3N and 4). In the Swedish example we studied apple/pear and juice/nectar consumption and residue levels of compound C (annex 3S). Extreme consumption and residue levels were introduced by multiplying the highest consumption level ( $810 \mathrm{~g}$ for apple in the Netherlands and $2200 \mathrm{~g}$ for juice/nectar in Sweden) and residue level (1.0 $\mathrm{mg} \mathrm{kg}^{-1}$ in the Netherlands and $0.36 \mathrm{mgkg}^{-1}$ in Sweden) in the data set with 2, 3 and 4. Variability was not included in the analyses.

It was clear that introducing an extreme consumption level in the data influenced in this example mainly the maximum exposure level sampled (tables 7AN and 7AS). The percentiles of exposure $(\leq$ P99.99) were rather insensitive to the change. When introducing a high residue level, however, the P99, P99.9 and P99.99 were influenced. For example both the P99.9 and P99.99 increased more than 3 -fold in both countries. The number of consumption and residue levels available for the analysis can explain this difference. For the Netherlands in total 12,500 consumption levels (consumers and nonconsumers) and only 27 residue levels were available. Changing a level in the residue dataset will therefore have a larger impact on the exposure assessment than changing one level in a large consumption dataset (see also below). This also applies to the Swedish calculations.

Also here it is important to visualise those consumption and residue levels that contribute to the

Table 7AS. Effect of introducing an extreme consumption or residue level on the acute exposure $\left(\mu \mathrm{g} \mathrm{kg}^{-1} \cdot \mathrm{d}^{-1}\right)$ in the Swedish population, including consumers and non-consumers (work example 7).

\begin{tabular}{rcccc}
\hline & \multicolumn{5}{c}{ factor } \\
\cline { 2 - 5 } variable and percentile & $1^{1}$ & 2 & 3 & 4 \\
\hline extreme consumption & & & & \\
P95 & 1.5 & 1.5 & 1.5 & 1.5 \\
P97.5 & 2.0 & 2.0 & 2.0 & 2.0 \\
P99 & 2.7 & 2.7 & 2.7 & 2.7 \\
P99.9 & 5.0 & 5.0 & 4.9 & 5.0 \\
P99.99 & 7.9 & 7.7 & 7.9 & 9.5 \\
max $^{2}$ & 12 & 23 & 37 & 46 \\
P95 & 1.5 & 1.6 & 1.7 & 1.7 \\
P97.5 & 2.0 & 2.2 & 2.4 & 2.6 \\
P99 & 2.7 & 3.2 & 3.5 & 4.3 \\
P99.9 & 5.1 & 6.8 & 9.2 & 12 \\
P99.99 & 7.6 & 11 & 16 & 22 \\
max & 12 & 24 & 27 & 34 \\
\hline
\end{tabular}

\footnotetext{
${ }^{1}$ highest consumption / residue level in data set multiplied with $1,2,3$, and 4 .

${ }^{2}$ max $=$ maximum exposure level sample
} 
Table 7BN. Sampled field trial residue levels $\left(\mathrm{mg}^{\cdot \mathrm{kg}^{-1}}\right.$ ) and consumption levels ( $\mathrm{g}$ ) belonging to the ten highest exposure levels simulated for the general Dutch population. Extreme values were introduced by multiplying the highest consumption $(=1700 \mathrm{~g})$ and highest field trial residue level $\left(=0.36 \mathrm{mg} \mathrm{kg}^{-1}\right)$ in the data set with 4 (work example 7).

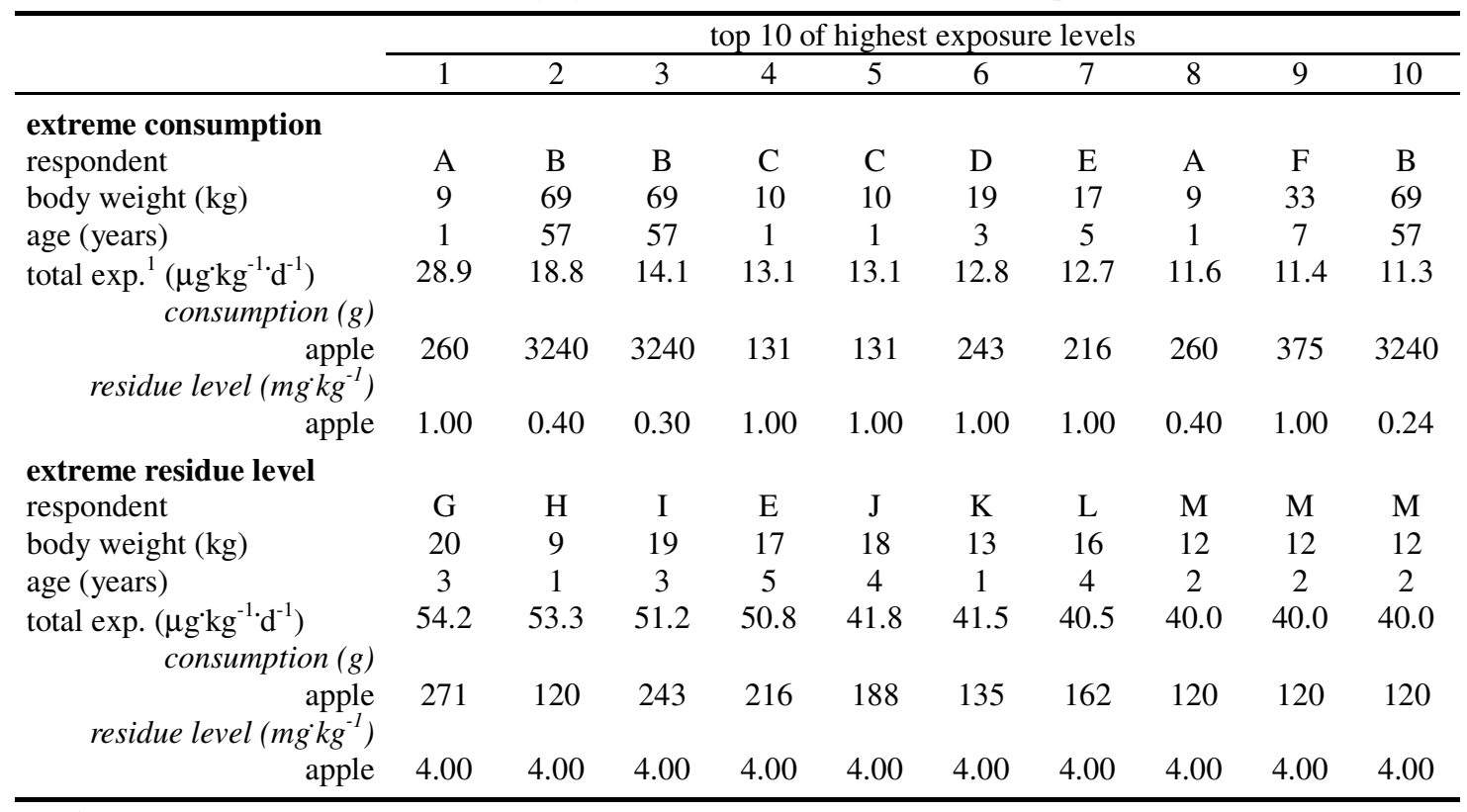

\footnotetext{
${ }^{1}$ exp. $=$ exposure
}

highest exposures. Especially when the reference point of the distribution (e.g. P99.9) exceeds the ARfD. In tables 7BN and 7BS the 10 highest exposure levels are listed with corresponding consumption and residue levels simulated, where an extreme consumption or residue level was introduced by multiplying the highest levels with 4 . It is evident that the extreme levels, both for consumption and residue, contribute to the highest 10 exposures simulated. Apart from showing how these outliers influence the upper part of the distribution it is also important to perform a quality check of the data, and to discuss the meaning of these outliers on a possible decision about the compound addressed.

The influence of e.g. a reporting mistake, an analytical error and / or a real high consumption and / or residue level on the exposure assessment will depend on the magnitude of the data set used. The larger the data set the smaller the effect will be. Outliers will influence especially the higher percentiles. Also the magnitude of the outlier will influence the effect on the upper percentiles.

\section{Bootstrap sampling}

Another method to study the stability of the tail of the exposure distribution is bootstrap sampling [14]. This is a method to assess the reliability of percentiles of exposure. Simply said, with this method a sample of $\mathrm{n}$ observations (e.g. food consumption levels, residue levels) is resampled from the original database to obtain a bootstrap sample of $n$ observations. Sampling is performed with replacement, so that every observation can occur more than once in the bootstrap sample. By repeating this process say 100 times, one obtains 100 bootstrap samples, which may be considered as alternative data sets that might have been obtained during sampling from the population of interest. Each statistic that can be calculated from the original data set (e.g. P50, P95) can also be calculated from each 
Table 7BS. Sampled consumption levels ( $\mathrm{g}$ ) and field trial residue levels $\left(\mathrm{mg}^{\circ} \mathrm{kg}^{-1}\right)$ belonging to the ten highest exposure levels simulated for the Swedish population. Extreme values were introduced by multiplying the highest consumption $(=2200 \mathrm{~g})$ and highest field trial residue level $\left(=0.36 \mathrm{mg}^{\circ} \mathrm{kg}^{-}\right.$ ${ }^{1}$ ) in the data set with 4 (work example 7).

\begin{tabular}{|c|c|c|c|c|c|c|c|c|c|c|}
\hline & \multicolumn{10}{|c|}{ top 10 of highest exposure levels } \\
\hline & 1 & 2 & 3 & 4 & 5 & 6 & 7 & 8 & 9 & 10 \\
\hline \multicolumn{11}{|l|}{ extreme consumption } \\
\hline respondent & A & A & A & A & A & A & A & A & A & A \\
\hline body weight (kg) & 65 & 65 & 65 & 65 & 65 & 65 & 65 & 65 & 65 & 65 \\
\hline age (years) & 18 & 18 & 18 & 18 & 18 & 18 & 18 & 18 & 18 & 18 \\
\hline total exp. ${ }^{1}\left(\mu \mathrm{g}^{\cdot} \mathrm{kg}^{-1} \cdot \mathrm{d}^{-1}\right)$ & 46.0 & 43.3 & 37.9 & 37.9 & 32.5 & 24.4 & 24.4 & 16.3 & 13.5 & 10.8 \\
\hline \multicolumn{11}{|l|}{ consumption $(\mathrm{g})$} \\
\hline apple/pear & - & - & - & - & - & - & - & - & - & - \\
\hline juice/nectar & 8800 & 8800 & 8800 & 8800 & 8800 & 8800 & 8800 & 8800 & 8800 & 8800 \\
\hline \multicolumn{11}{|l|}{ residue level $\left(\mathrm{mg}^{*} \mathrm{~kg}^{-1}\right)$} \\
\hline apple and pear & - & - & - & - & - & - & - & - & - & - \\
\hline juice and nectar & 0.34 & 0.32 & 0.28 & 0.28 & 0.24 & 0.18 & 0.18 & 0.12 & 0.10 & 0.08 \\
\hline \multicolumn{11}{|l|}{ extreme residue level } \\
\hline respondent & B & $\mathrm{C}$ & $\mathrm{D}$ & $\mathrm{E}$ & $\mathrm{F}$ & $\mathrm{G}$ & $\mathrm{H}$ & $\mathrm{I}$ & $\mathrm{J}$ & $\mathrm{J}$ \\
\hline body weight (kg) & 66 & 73 & 60 & 50 & 60 & 60 & 62 & 58 & 65 & 65 \\
\hline age (years) & 20 & 54 & 37 & 52 & 30 & 17 & 19 & 75 & 30 & 30 \\
\hline total exp. $\left(\mu \mathrm{g}^{*} \mathrm{~kg}^{-1} \cdot \mathrm{d}^{-1}\right)$ & 33.6 & 31.6 & 29.4 & 28.8 & 26.5 & 24.0 & 23.2 & 22.7 & 22.2 & 22.2 \\
\hline \multicolumn{11}{|l|}{ consumption $(g)$} \\
\hline apple/pear & 105 & - & 315 & - & 105 & - & - & 315 & - & - \\
\hline juice/nectar & 1530 & 1600 & 1200 & 1000 & 1000 & 1000 & 1000 & 600 & 1000 & 1000 \\
\hline \multicolumn{11}{|l|}{ residue level ( $\left.\mathrm{mg}^{*} \mathrm{~kg}^{-1}\right)$} \\
\hline apple/pear & 0.16 & - & 0.12 & - & 1.44 & - & - & 1.44 & - & - \\
\hline juice/nectar & 1.44 & 1.44 & 1.44 & 1.44 & 1.44 & 1.44 & 1.44 & 1.44 & 1.44 & 1.44 \\
\hline
\end{tabular}

bootstrap sample. This will generate a bootstrap distribution of 100 P50s, P95s, etc. The bootstrap distribution now characterises the uncertainty due to the sampling uncertainty of the original data set.

\section{Conclusion}

In work example 6 we demonstrated the effect of the number of iterations on the stability of the tail. The upper percentiles will become more reliable when you increase the number of iterations (in our example $\geq 50,000$ ). Work example 7 showed the effect of an outlier (extreme consumption or residue level) on the stability of the tail. It was clear that an outlier affects the result depending on the magnitude of the outlier compared to the other data and on the largeness of the data set available. This effect will be more visible on the P99.9, P99.99 and maximum exposure level simulated than on the P99. When outliers are present in the data, it is always important to visualise them (quality check), and to discuss the meaning of these outliers on a possible decision about the compound addressed. 


\section{CONCLUSIONS}

Based on the work examples performed by the Netherlands and Sweden, the following conclusions can be drawn:

1. Work example 1: Point estimates result in higher estimates of exposure than the probabilistic approach. The probabilistic approach takes a more holistic approach to risk, by addressing all consumption levels, all residue levels and all foods contributing to the exposure to a compound simultaneously into the exposure assessment.

2. Work example 2: Addressing more than one food using the 'consumers only' concept may result in a lower overall exposure level compared to the exposure from one food. This may hamper a clear risk management decision.

3. Work example 3: Including processing in the analyses affects the exposure assessment and should therefore be included in the exposure calculations if information is available. A probabilistic approach enables the risk assessor to address combinations of foods that may contain the compound of interest in one analysis, as well as different types of processing of one food. This is not possible in the point estimate.

4. Work example 4: Variability can be included in the probabilistic analyses via different ways, resulting in different outcomes. The way presented here as the beta distribution reflects the most realistic situation (residue levels of individual units can be either lower, equal or higher than the corresponding composite sample level and the maximum residue level to be sampled is bound at an upper level).

5. Work example 5: Exceedance of the ARfD at the critical percentile of exposure should be discussed in relation to the uncertainties in the database, and should also be seen in relation to the uncertainty factors used in the derivation of the ARfD.

6. Work example 6: The number of iterations should be large enough to result in estimations of upper percentiles (e.g. P95, P97.5, P99, P99.9, P99.99) that do not fluctuate substantially.

7. Work example 7: The influence of the presence of an outlier or outliers (extreme high consumption and / or residue level) in the analyses depends on the size of the data set used. The larger the data set, the smaller the effect. If outliers are present especially the higher percentiles are influenced ( $\geq$ P99.9). The software used for probabilistic modelling should be able to visualise the upper part of the exposure distribution (e.g. top 10) in order to check the quality of the data.

8. Overall we conclude that this document demonstrates clearly the potential of the probabilistic approach compared to the current methodology used, when assessing the acute dietary exposure to pesticides. Different aspects were addressed to help risk managers to better understand and to interpret the results of a probabilistic exposure assessment. The results of this document form the basis for the development of draft guidelines on the use of probabilistic exposure assessment in the safety evaluation of pesticides in the EU-market. 


\section{References}

[1] SCP, Opinion of the Scientific Committee on Plants regarding the inclusion of aldicarb in Annex 1 to Directive 91/414/EEC concerning the placing of plant protection products in the market, Scientific Committee on Plants, EU, Brussels, 1998.

[2] H. van der Voet, P.E. Boon, J.D. van Klaveren, Validation of Monte Carlo models for estimating pesticide intake in Dutch infants, Report no. 2003.002, RIKILT - Institute of Food Safety, Wageningen UR, Wageningen, 2003.

[3] P.E. Boon, H. van der Voet, J.D. van Klaveren, Validation of a probabilistic model of dietary exposure to selected pesticides in Dutch infants, Food Additives and Contaminants 20(Suppl 1) (2003) 36-49.

[4] Anonymous, Zo eet Nederland, Resultaten van de voedselconsumptiepeiling 1997 - 1998 [Results of the Dutch National Food Consumption Survey 1997-1998], Voedingscentrum, Den Haag, 1998.

[5] C. Kistemaker, M. Bouman, K.F.A.M. Hulshof, De consumptie van afzonderlijke producten door Nederlandse bevolkingsgroepen - Voedselconsumptiepeiling 1997-1998 [Consumption of food products by Dutch population groups - Dutch National Food Consumption Survey 1997-1998], Report no. V98.812, TNO-Voeding, Zeist, 1998.

[6] M.M.H. van Dooren, I. Boeijen, J.D. van Klaveren, G.. van Donkersgoed, Conversie van consumeerbare voedingsmiddelen naar primaire agrarische produkten [Conversion of foods to primary agricultural products], Report no. 95.17, RIKILT, Wageningen, 1995.

[7] W. Becker, Riksmaten 1997 - 1998, Svenskarna äter nyttigare - allt fler väljer grönt [Riksmaten 1997 - 1998. The Swedes eat more healthy]. Voar Föda, 51 (1999) 24-27.

[8] FAO/WHO, Pesticides residues - Submission and evaluation of pesticide residues data for the estimation of maximum residue levels in food and feed, FAO Plant Production and Protection Paper 170, Rome, 2002.

[9] FAO/WHO, Pesticide Residues in Food - 2003. Report of the Joint Meeting of the FAO Panel of Experts on Pesticide Residues in Food and the Environment and the WHO Core Assessment Group, FAO Plant Production and Protection Paper, 176, Rome, 2004.

[10] H. van der Voet, W.J. de Boer, P.E. Boon, G. van Donkersgoed, J.D. van Klaveren, MCRA, a webbased program for Monte Carlo Risk Assessment, Release 3, Reference Guide, Biometris and RIKILT, Wageningen UR, Wageningen, 2004, available at www2.rikilt.dlo.nl/mcra/mcra.html.

[11] EPA, Choosing a percentile of acute dietary exposure as a threshold of regulatory concern, Report no. 6046, US Environmental Protection Agency, Washington DC, 2000.

[12] FAO/WHO, Food consumption and exposure assessment of chemicals, Report of a joint FAO/WHO Consultation (WHO/FSF/FOS/97.5), World Health Organization, Geneva, 10-14 February 1997.

[13] CCPR, Dietary exposure in relation to MRL setting: discussion paper on proposals for improvement methodology for point estimates of acute intake of pesticide residues (CX/PR 03/3), Rotterdam: Codex Alimentarius Commission, 2003.

[14] B. Efron, R. Tibshirani, An introduction to the bootstrap, Chapman \& Hall, New York, 1993. 
ANNEX 1. Point estimate approach.

The equation as defined in the FAO Manual on the Submission and Evaluation of Pesticide Residue Data and used by the Joint FAO/WHO Meeting on Pesticide Residues (JMPR; [1]):

$$
\{\mathrm{U} * \mathrm{HR}(-\mathrm{P}) * v\}+\{(\mathrm{LP}-\mathrm{U}) * \mathrm{HR}(-\mathrm{P})\}
$$

International Short-Term Intake (IESTI) $=$

bw

\section{where:}

$\mathrm{U}=$ unit weight of edible portion $(\mathrm{kg})$ or if the large portion consumption is less than one commodity unit than $\mathrm{U}$ is equal to the large portion consumption and the second term of the equation drops out.

$\mathrm{HR}(-\mathrm{P}) \quad=$ highest residue level in composite sample of edible portion (HR; $\mathrm{mgkg}^{-1}$ ), or corrected for processing (HR-P) calculated by multiplying the HR in the raw commodity by the processing factor.

$v \quad=$ variability factor; when applying the default variability factor the unit weight on a whole commodity is used to decide the choice of variability factor, not the edible portion unit weight.

LP = largest portion reported (eaters at P97.5 of consumption), kg per day. Where LP is less than or equal to $\mathrm{U}$, the second term of the equation drops out.

bw $\quad=$ mean body weight of the target population subgroup, $\mathrm{kg}$.

Default variability factors as defined for use in the point estimate (WHO GEMS/Food web site for acute exposure, address: www.who.int/foodsafety/chem/acute_data/en/):

unit weight of whole portion $>250 \mathrm{~g}$, except head cabbage:

$v=5$

$25 \leq$ unit weight of whole portion $\leq 250 \mathrm{~g}$ :

$v=7$

unit weight of whole portion $\leq 250 \mathrm{~g}$ from granular soil treatment:

$v=10$

Leafy vegetables, unit weight of whole portion $\leq 250 \mathrm{~g}$, except head lettuce:

$v=10$

Head lettuce and head cabbage:

$v=3$

When sufficient data are available on residues in each unit to calculate a more realistic variability factor for a commodity, the calculated value should replace the default value.

\section{References}

[1] FAO/WHO, Pesticide residues - Submission and evaluation of pesticide residues data for the estimation of maximum residue levels in food and feed, FAO Plant Production and Protection Paper 170, Rome, 2002. 
ANNEX 2. Variability in residue levels within composite samples.

Because hardly any data are available on variability in residue levels between individual units of composite samples, we applied default variability factors, as defined on the WHO GEMS/food website $^{3}$ (annex 1), in the point estimate. In the point estimate one single value for variability is applied. In the probabilistic approach however, one single value for variability cannot be used as such in single simulations of a probabilistic exposure analysis. Due to lack of guidelines on how to apply variability in a probabilistic approach, we incorporated variability in the analyses following the procedure described below, indicated as the 'beta way'.

We simulated new residue levels using the beta distribution. This means that the simulated residue levels are sampled from a bounded distribution. The lowest residue level sampled is $0 \mathrm{mg} \mathrm{kg}^{-1}$, and the maximum level sampled is equal to the level of the composite sample multiplied with the number of units in the composite sample. So e.g. for orange the number of units in a composite equals 12 (EUDirective 7029/VI/95 rev.5: annex B). For each field trial residue level sampled per unit orange consumed (e.g. 0.01, 0.01, 0.02, etc) a beta distribution is generated bounded by $0 \mathrm{mg}^{\mathrm{kg}} \mathrm{kg}^{-1}$ and 12 times the residue level of the composite sample. Every possible residue level between these two levels can be sampled and used in the exposure calculations. In this way the situation in real life is mimicked as best as possible using the original definition of the default variability factors as defined in the point estimate [1]. To apply the beta distribution for simulating new residue levels information is needed on the variability factor (default value) and the number of units in a composite sample. For more details, see [2].

In $\S 3.3$ we also incorporated variability into the analyses described as the 'lognormal' way and the 'Bernoulli' way. In the lognormal way, new residue levels were simulated using a lognormal distribution. The main difference with the beta distribution is that there is no upper limit anymore to the maximum residue level that can be sampled. As in the beta distribution, also in the lognormal distribution the parameter for unit variability was by a variability factor and the number of units in a composite sample. For more details, see [2].

In the 'Bernoulli way' the programme sampled for each unit consumed a field trial residue level from the residue database that was either multiplied with the default variability factor or left alone. In the case of orange with a default variability factor of 7 , multiplication of the residue level with 7 occurred with a probability of $14 \%(=1 \div 7)$ and sampling of the field trial residue level itself occurred with a probability of $86 \%$ ( $=6 \div 7$; Bernoulli distribution). For more details, see [2]. Following this approach the residue level was either sampled as such or at a level 7 times higher (in the case of e.g. orange). Sampling residue levels lower than the field trial residue level (as is possible following the 'beta way') was not possible, making this approach very conservative.

In all three approaches of incorporating variability into the probabilistic approach variability was applied to each individual unit consumed. It is therefore theoretically possible that a person consuming e.g. two units sampled a high residue level for both units. This is not possible in the point estimate [3].

\footnotetext{
${ }^{3}$ http://www.who.int/foodsafety/chem/acute_data/en/
} 
Variability was not applied to foods that were consumed after the raw agricultural commodity had undergone some kind of industrial bulking or blending, e.g. fruit juices or fruit sauces. This is in accordance with the guidelines for the point estimate [3].

\section{References}

[1] FAO/WHO, Food consumption and exposure assessment of chemicals, Report of an joint FAO/WHO Consultation (WHO/FSF/FOS/97.5), World Health Organisation , Geneva, 10-14 February 1997.

[2] H. van der Voet, W.J. de Boer, P.E. Boon, G. van Donkersgoed, J.D. van Klaveren, MCRA, a GenStat program for Monte Carlo Risk Assessment, Release 2, Reference Guide, Wageningen, Biometris and RIKILT - Institute of Food Safety, Wageningen UR, Wageningen, 2004, available at www2.rikilt.dlo.nl/mcra/mcra.html.

[3] FAO/WHO, Pesticide residues - Submission and evaluation of pesticide residues data for the estimation of maximum residue levels in food and feed, FAO Plant Production and Protection Paper 170, Rome, 2002. 
ANNEX 3N. Characteristics of the different foods used in the calculations of the acute dietary exposure with the point estimate and the probabilistic approach in the Dutch work examples.

In the different tables (annex $3 \mathrm{~N}$ and $3 \mathrm{~S}$ ) the following abbreviations are used:

$\mathrm{HR}=$ highest residue level in edible portion of the commodity;

STMR = supervised trials median residue level;

LP $=$ large portion size (defined as the $97.5^{\text {th }}$ percentile of consumption of consumers only);

$\mathrm{bw}=$ body weight

compound A:

\begin{tabular}{llcc}
\hline characteristics & \multicolumn{1}{c}{ apple } & kiwi & orange \\
\hline residue level $\left(\mathrm{mg}^{\cdot} \mathrm{kg}^{-1}\right)$ & $0.01(6), 0.02(4), 0.04(4)$, & $0.03(3), 0.04(9), 0.06(5)$, & $0.1(4), 0.2(6), 0.3(4), 0.4$, \\
& $0.06(5), 0.07,0.08,0.09(2)$, & $0.07,0.09(5), 0.1(4)$, & $0.5(2), 0.6,0.7(2), 0.8(4)$, \\
& $0.1(3), 0.2(3), 0.3$ & $0.2(10), 0.3(2), 0.4$ & $0.9(2), 1.0(3), 1.3,1.5,1.8$, \\
$\mathrm{HR}\left(\mathrm{mg}^{\prime} \mathrm{kg}^{-1}\right)$ & & & $2.8,3.3(2), 3.6(2)$ \\
unit wt $(\mathrm{g})$ & 0.3 & 0.4 & 3.6 \\
net edible portion wt $(\mathrm{g})$ & 126 & 75 & 229 \\
variability factor & 112 & 64 & 160 \\
LP general population $(\mathrm{g})$ & 7 & 7 & 7 \\
LP children (1 - 6 years) $(\mathrm{g})$ & 316 & 150 & 340 \\
bw general population $(\mathrm{kg})$ & 260 & 150 & 65.8 \\
bw children (1 - 6 years) $(\mathrm{kg})$ & 65.8 & 65.8 & 17.1 \\
\hline
\end{tabular}

compound B:

\begin{tabular}{|c|c|c|c|c|}
\hline characteristics & carrot & cauliflower & mandarin & tomato \\
\hline residue level $\left(\mathrm{mg}^{\cdot} \mathrm{kg}^{-1}\right)$ & $\begin{array}{l}0.03,0.04,0.05, \\
0.1(4), 0.2(3), 0.3, \\
0.4(2), 0.5,0.7 \\
0.9,1.1(2), 1.2,2\end{array}$ & $\begin{array}{l}0.1(3), 0.4,0.6(3), \\
1.0,1.1,1.3,1.5, \\
1.8,2.4(2), 2.7(2), \\
3.9\end{array}$ & $\begin{array}{l}0.1,0.2(3), 0.3 \\
0.4(2), 0.5,1.3 \\
1.6(2), 1.7,1.8(2) \\
2.1(2), 2.2(2), 2.3 \\
2.8,3.2(2), 4.0,5.0\end{array}$ & $\begin{array}{l}0.2,0.3,0.4,0.7(2), \\
1.2(3), 1.5(2), 1.9, \\
2.2,2.5,2.7,3.1, \\
3.2(2), 3.6,3.8,4.0, \\
4.1\end{array}$ \\
\hline $\mathrm{HR}\left(\mathrm{mg}^{\cdot} \mathrm{kg}^{-1}\right)$ & 2 & 3.9 & 5 & 4.1 \\
\hline unit wt (g) & 114 & 1733 & 133 & 85 \\
\hline net edible portion wt $(\mathrm{g})$ & 80 & 780 & 100 & 85 \\
\hline variability factor & 7 & 5 & 7 & 7 \\
\hline LP general population $(\mathrm{g})$ & 300 & 400 & 210 & 231 \\
\hline LP children $(1-6$ years $)(\mathrm{g})$ & 155 & 226 & 165 & 77 \\
\hline bw general population $(\mathrm{kg})$ & 65.8 & 65.8 & 65.8 & 65.8 \\
\hline bw children $(1-6$ years $)(\mathrm{kg})$ & 17.1 & 17.1 & 17.1 & 17.1 \\
\hline
\end{tabular}


compound $\mathrm{C}$ :

\begin{tabular}{|c|c|c|}
\hline \multirow[b]{2}{*}{ characteristics } & \multicolumn{2}{|c|}{ apple } \\
\hline & with / without peel & juicing \\
\hline residue level $\left(\mathrm{mg}^{\circ} \mathrm{kg}^{-1}\right)$ & $\begin{array}{l}0.06(2), 0.08,0.1(2), \\
0.12(5), 0.16(3), 0.18(3), \\
0.2,0.22,0.24(3), 0.28,0.3 \text {, } \\
0.32(2), 0.34,0.36\end{array}$ & $\begin{array}{l}0.06(2), 0.08,0.1(2), \\
0.12(5), 0.16(3), 0.18(3), \\
0.2,0.22,0.24(3), 0.28,0.3 \text {, } \\
0.32(2), 0.34,0.36\end{array}$ \\
\hline $\mathrm{HR}\left(\mathrm{mg}^{\cdot} \mathrm{kg}^{-1}\right)$ & 0.36 & - \\
\hline $\operatorname{STMR}\left(\mathrm{mg}^{\cdot} \mathrm{kg}^{-1}\right)$ & - & 0.18 \\
\hline unit wt (g) & 126 & - \\
\hline net edible portion wt $(\mathrm{g})$ & 112 & - \\
\hline variability factor & 7 & 1 \\
\hline LP general population (g) & 316 & 896 \\
\hline LP children $(1-6$ years $)(g)$ & 260 & 800 \\
\hline bw general population $(\mathrm{kg})$ & 65.8 & 65.8 \\
\hline bw children $(1-6$ years $)(\mathrm{kg})$ & 17.1 & 17.1 \\
\hline
\end{tabular}

compound D:

\begin{tabular}{lc}
\hline characteristics & apple \\
\hline residue level $\left(\mathrm{mg}^{\cdot} \mathrm{kg}^{-1}\right)$ & $0.1(3), 0.2(11), 0.3(6)$, \\
& $0.4(4), 0.6(3), 0.7(2), 0.8$ \\
$\mathrm{HR}\left(\mathrm{mg}^{-1} \mathrm{~kg}^{-1}\right)$ & 0.8 \\
$\mathrm{STMR}\left(\mathrm{mg} \cdot \mathrm{kg}^{-1}\right)$ & - \\
unit wt $(\mathrm{g})$ & 126 \\
net edible portion wt $(\mathrm{g})$ & 112 \\
variability factor & 7 \\
processing factor & 0.1 \\
LP general population $(\mathrm{g})$ & 316 \\
LP children $(1-6$ years $)(\mathrm{g})$ & 260 \\
bw general population $(\mathrm{kg})$ & 65.8 \\
bw children $(1-6$ years $)(\mathrm{kg})$ & 17.1 \\
\hline
\end{tabular}

compound $\mathbf{E}$ :

\begin{tabular}{|c|c|c|c|c|c|}
\hline characteristics & beetroot & cucumber & grapefruit & head lettuce & pear \\
\hline residue level $\left(\mathrm{mg}^{*} \mathrm{~kg}^{-1}\right)$ & $\begin{array}{l}0.06(7), 0.1(2), \\
0.12(3), 0.22\end{array}$ & $\begin{array}{l}0.05(5), 0.1(21), \\
0.15,0.45\end{array}$ & $\begin{array}{l}0.29,0.41(2), \\
0.46,0.95,1.25, \\
1.3,1.4,1.6(2), \\
1.7,1.8,1.9, \\
2.1(2), 2.2, \\
2.3(2), 2.4,2.5, \\
2.6,2.8,2.9, \\
3.3(2), 4.1,5\end{array}$ & $\begin{array}{l}0.02(2), 0.03, \\
0.05,0.06(2), \\
0.07(2), 0.08(2), \\
0.09(4), 0.1, \\
0.11,0.12,0.13, \\
0.14,0.16, \\
0.17(2), 0.19, \\
0.24,0.25,0.28, \\
0.31(2), 0.33, \\
0.38,0.4,0.49, \\
0.95\end{array}$ & $\begin{array}{l}0.51,0.55(2), \\
0.61,0.65,0.66, \\
0.68,0.69(2), \\
0.7,0.77, \\
0.78(2), 0.86, \\
0.87,0.88,0.96, \\
1(3), 1.1(2), \\
1.2(3), 1.3(3), \\
1.4,1.5(4), 1.7, \\
1.8,1.9,2.1(2), \\
2.3,2.9\end{array}$ \\
\hline unit wt (g) & 44 & 400 & 340 & 754 & 187 \\
\hline net edible portion wt $(\mathrm{g})$ & 35 & 360 & 160 & 558 & 170 \\
\hline variability factor & 7 & 5 & 5 & 3 & 7 \\
\hline
\end{tabular}


ANNEX 3S. Characteristics of the different food items and summary statistics of the food consumption levels used in the calculations of acute dietary exposure with the point estimate and the probabilistic approach in the Swedish work examples.

For abbreviations used, see annex $3 \mathrm{~N}$

compound $\mathrm{A}$ :

\begin{tabular}{lccc}
\hline & apple/pear & kiwi & $\begin{array}{c}\text { orange/small citrus/ } \\
\text { grapefruit }\end{array}$ \\
\hline residue levels $\left(\mathrm{mg}^{\mathrm{k}} \mathrm{kg}^{-1}\right)$ & & & $0.1(4), 0.2(6), 0.3(4)$, \\
& $0.01(6), 0.02(4)$, & $0.03(3), 0.04(9)$, & $0.4,0.5(2), 0.6,0.7(2)$, \\
& $0.04(4), 0.06(5)$, & $0.06(5), 0.07$, & $0.8(4), 0.9(2), 1.0(3)$, \\
& $0.07,0.08$, & $0.09(5), 0.1(4)$, & $1.3,1.5,1.8,2.8,3.3(2)$, \\
HR (mg'kg-1) & $0.09(2), 0.1(3)$, & $0.2(10), 0.3(2), 0.4$ & $3.6(2)$ \\
unit wt (g) & $0.2(3), 0.3$ & & 3.6 \\
net edible portion (g) & 0.3 & 75 & 229 \\
variability factor & 126 & 64 & 160 \\
consumption data & 112 & 7 & 7 \\
mean level (g/day) & 7 & & 34 \\
mean level, consumers only (g) & & 2.9 & 157 \\
minimum level, consumers only $(\mathrm{g})$ & 43 & 76 & 10 \\
maximum level (g/day) & 145 & 15 & 1250 \\
LP (g) & 10 & 260 & 400 \\
number of consumption days & 735 & 130 & 1866 \\
number of consumers & 315 & 321 & 571 \\
bw (kg) & 2484 & 151 & 73 \\
\hline
\end{tabular}

compound B:

\begin{tabular}{|c|c|c|c|c|}
\hline characteristics & carrot & $\begin{array}{c}\text { cauliflower/ } \\
\text { Brussels } \\
\text { sprouts/ broccoli }\end{array}$ & peach/nectarine & tomato \\
\hline residue level $\left(\mathrm{mg}^{*} \mathrm{~kg}^{-1}\right)$ & $\begin{array}{l}0.03,0.04, \\
0.05,0.1(4), \\
0.2(3), 0.3, \\
0.4(2), 0.5, \\
0.7,0.9, \\
1.1(2), 1.2,2\end{array}$ & $\begin{array}{l}0.1(3), 0.4, \\
0.6(3), 1.0,1.1, \\
1.3,1.5,1.8 \\
2.4(2), 2.7(2) \\
3.9\end{array}$ & $\begin{array}{l}0.1,0.2(3), 0.3, \\
0.4(2), 0.5,1.3, \\
1.6(2), 1.7, \\
1.8(2), 2.1(2), \\
2.2(2), 2.3,2.8, \\
3.2(2), 4.0,5.0\end{array}$ & $\begin{array}{l}0.2,0.3,0.4, \\
0.7(2), 1.2(3), \\
1.5(2), 1.9,2.2, \\
2.5,2.7,3.1, \\
3.2(2), 3.6,3.8, \\
4.0,4.1\end{array}$ \\
\hline $\mathrm{HR}\left(\mathrm{mg}^{\cdot} \mathrm{kg}^{-1}\right)$ & 2 & 3.9 & 5 & 4.1 \\
\hline unit wt (g) & 114 & 1733 & 122 & 85 \\
\hline net edible portion $(\mathrm{g})$ & 80 & 780 & 110 & 85 \\
\hline $\begin{array}{l}\text { variability factor } \\
\text { consumption data }\end{array}$ & 7 & 5 & 7 & 7 \\
\hline mean level $(\mathrm{g})$ & 9.8 & 2.8 & 5.0 & 26 \\
\hline mean level, consumers only (g) & 60 & 54 & 181 & 80 \\
\hline minimum level, consumers only $(\mathrm{g})$ & 15 & 15 & 65 & 8 \\
\hline maximum level $(\mathrm{g})$ & 1030 & 350 & 520 & 584 \\
\hline $\mathrm{LP}(\mathrm{g})$ & 120 & 120 & 520 & 260 \\
\hline number of consumption days & 1379 & 438 & 235 & 2730 \\
\hline number of consumers & 657 & 301 & 121 & 917 \\
\hline bw (kg) & 73 & 73 & 73 & 73 \\
\hline
\end{tabular}


compound $\mathrm{C}$ :

\begin{tabular}{|c|c|c|}
\hline & apple/pear & juice/nectar \\
\hline characteristics & with/without peel & \\
\hline residue level $\left(\mathrm{mg}^{\cdot} \mathrm{kg}^{-1}\right)$ & $\begin{array}{l}0.06(2), 0.08,0.1(2), 0.12(5), \\
0.16(3), 0.18(3), 0.2,0.22, \\
0.24(3), 0.28,0.3,0.32(2), \\
0.34,0.36\end{array}$ & $\begin{array}{l}0.06(2), 0.08,0.1(2), 0.12(5), \\
0.16(3), 0.18(3), 0.2,0.22, \\
0.24(3), 0.28,0.3,0.32(2), 0.34, \\
0.36\end{array}$ \\
\hline $\mathrm{HR}\left(\mathrm{mg}^{\cdot} \mathrm{kg}^{-1}\right)$ & 0.36 & - \\
\hline $\operatorname{STMR}(\mathrm{mg} / \mathrm{kg})$ & - & 0.18 \\
\hline unit wt (g) & 126 & - \\
\hline net edible portion $(\mathrm{g})$ & 112 & - \\
\hline variability factor & 7 & - \\
\hline \multicolumn{3}{|l|}{ consumption data } \\
\hline mean level $(\mathrm{g})$ & 43 & 86 \\
\hline mean level, consumers only (g) & 145 & 319 \\
\hline minimum level, consumers only (g) & 10 & 50 \\
\hline maximum level $(\mathrm{g})$ & 735 & 2200 \\
\hline $\mathrm{LP}(\mathrm{g})$ & 315 & 800 \\
\hline number of consumption days & 2484 & 2301 \\
\hline number of consumers & 762 & 701 \\
\hline bw $(\mathrm{kg})$ & 73 & 73 \\
\hline
\end{tabular}

compound D:

\begin{tabular}{lc}
\hline characteristics & apple/pear \\
\hline residue level $\left(\mathrm{mg}^{\cdot} \mathrm{kg}^{-1}\right)$ & $0.1(3), 0.2(11), 0.3(6), 0.4(4), 0.6(3), 0.7(2), 0.8$ \\
$\mathrm{HR}\left(\mathrm{mg}^{\cdot} \mathrm{kg}^{-1}\right)$ & 126 \\
unit wt $(\mathrm{g})$ & 112 \\
net edible portion $(\mathrm{g})$ & 7 \\
variability factor & \\
consumption data & 43 \\
$\quad$ mean level (g/day) & 145 \\
$\quad$ mean level, consumers only (g/day) & 10 \\
minimum level, consumers only (g/day) & 735 \\
$\quad$ maximum level (g/day) & 315 \\
large portion (g) & 2484 \\
$\quad$ number of consumption days & 762 \\
number of consumers & 73 \\
$\quad$ bw (kg) & \\
\hline
\end{tabular}


compound $\mathbf{E}$ :

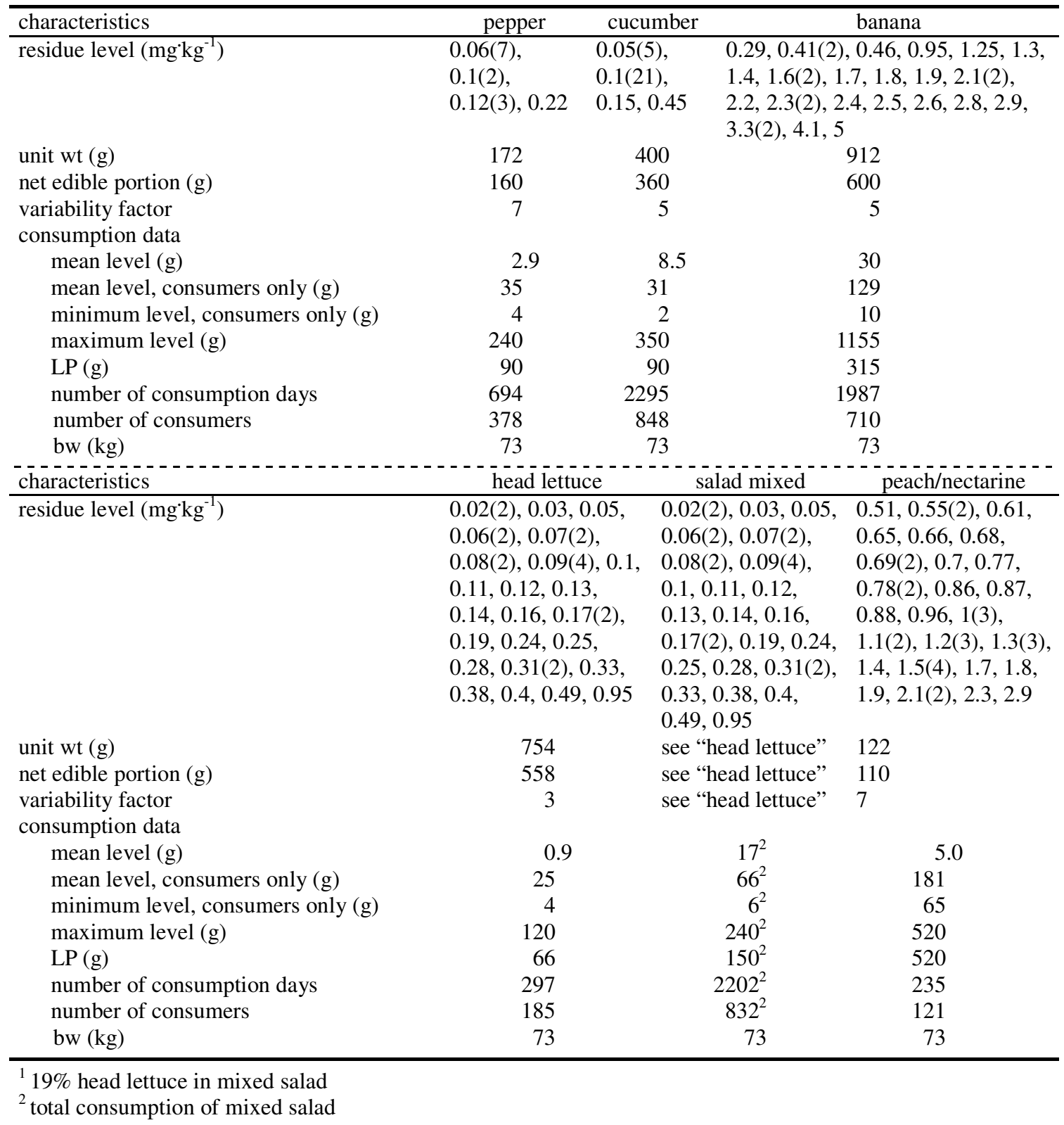


ANNEX 4. Summary statistics of the food consumption levels used in probabilistic modelling in the Dutch work examples.

\begin{tabular}{|c|c|c|c|c|c|c|c|c|c|c|c|c|}
\hline characteristics & apple & beetroot & carrot & cauliflower & cucumber & grapefruit & head lettuce & kiwi & mandarin & orange & pear & tomato \\
\hline \multicolumn{13}{|l|}{ general population (1-97 years) } \\
\hline mean level total population $(\mathrm{g})$ & 35.7 & 3.5 & 9.3 & 10.1 & 7.1 & 4.1 & 3.4 & 2.4 & 8.5 & 13.5 & 8.6 & 9.4 \\
\hline mean level cons. only ${ }^{1}(\mathrm{~g})$ & 135 & 51 & 116 & 195 & 56 & 28 & 34 & 80 & 74.8 & 139 & 32 & 69.0 \\
\hline minimum level cons. only (g) & 1.0 & 0.08 & 1.0 & 1.3 & 0.08 & 0.03 & 0.12 & 10 & 6.0 & 10 & 0.04 & 1.3 \\
\hline maximum level $(\mathrm{g})$ & 810 & 458 & 563 & 485 & 600 & 1150 & 301 & 300 & 605 & 480 & 808 & 485 \\
\hline number of consumption days & 3208 & 869 & 1004 & 645 & 1588 & 1803 & 1265 & 370 & 1419 & 1215 & 3380 & 1706 \\
\hline \multicolumn{13}{|l|}{ children (1-6 years) } \\
\hline mean level total population $(\mathrm{g})$ & 31.3 & 2.3 & 6.2 & 5.6 & 4.0 & 0.8 & 0.7 & 0.2 & 7.7 & 4.8 & 5.8 & 2.5 \\
\hline mean level cons. only (g) & 103 & 32 & 77.6 & 117 & 44 & 1.8 & 23 & 68 & 62.4 & 102 & 10 & 34.0 \\
\hline minimum level cons. only ( $\mathrm{g}$ ) & 2.0 & 0.08 & 8.9 & 24 & 0.08 & 0.1 & 3.4 & 10 & 8.0 & 12 & 0.1 & 2.6 \\
\hline maximum level (g) & 360 & 172 & 250 & 226 & 242 & 130 & 71 & 150 & 360 & 200 & 300 & 137 \\
\hline number of consumption days & 323 & 75 & 85 & 51 & 96 & 445 & 34 & 45 & 131 & 50 & 591 & 79 \\
\hline
\end{tabular}

\begin{tabular}{|c|c|}
\hline characteristics & apple juice \\
\hline \multicolumn{2}{|l|}{ general population (1-97 years) } \\
\hline mean level total population $(\mathrm{g})$ & 15.6 \\
\hline mean level cons. only ${ }^{1}(\mathrm{~g})$ & 266 \\
\hline minimum level cons. only (g) & 15 \\
\hline maximum level (g) & 1700 \\
\hline number of consumption days & 731 \\
\hline \multicolumn{2}{|l|}{ children (1-6 years) } \\
\hline mean level total population $(\mathrm{g})$ & 45 \\
\hline mean level cons. only (g) & 239 \\
\hline minimum level cons. only ( $\mathrm{g}$ ) & 40 \\
\hline maximum level (g) & 1080 \\
\hline number of consumption days & 201 \\
\hline
\end{tabular}

${ }^{1}$ cons. only $=$ consumers only 
RIKILT Rapportnummer 2004.008 